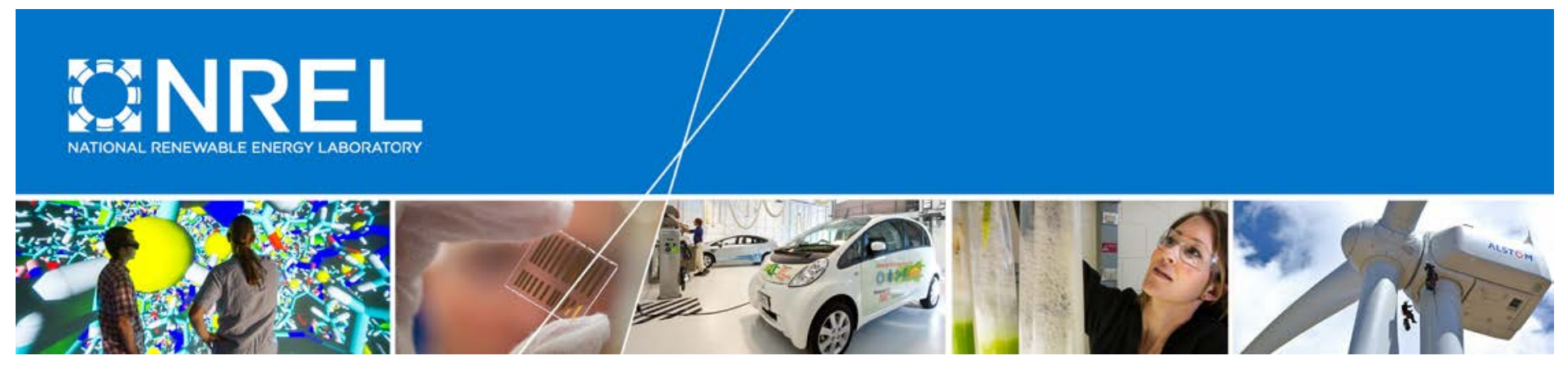

\title{
Sulfate Salts in Gasoline and Ethanol Fuels - Historical Perspective and Analysis of Available Data
}

Robert L. McCormick and Teresa L. Alleman National Renewable Energy Laboratory

Janet Yanowitz

Ecoengineering, Inc.

NREL is a national laboratory of the U.S. Department of Energy Office of Energy Efficiency \& Renewable Energy Operated by the Alliance for Sustainable Energy, LLC

This report is available at no cost from the National Renewable Energy Laboratory (NREL) at www.nrel.gov/publications.

Technical Report

NREL/TP-5400-69001

September 2017

Contract No. DE-AC36-08G028308 


\title{
Sulfate Salts in Gasoline and Ethanol Fuels - Historical Perspective and Analysis of Available Data
}

\author{
Robert L. McCormick and Teresa L. Alleman \\ National Renewable Energy Laboratory \\ Janet Yanowitz \\ Ecoengineering, Inc.
}

Prepared under Task No. VTOP.10335.04.01.03

NREL is a national laboratory of the U.S. Department of Energy Office of Energy Efficiency \& Renewable Energy Operated by the Alliance for Sustainable Energy, LLC

This report is available at no cost from the National Renewable Energy Laboratory (NREL) at www.nrel.gov/publications.

National Renewable Energy Laboratory 15013 Denver West Parkway Golden, CO 80401

303-275-3000 • www.nrel.gov
Technical Report

NREL/TP-5400-69001

September 2017

Contract No. DE-AC36-08G028308 


\section{NOTICE}

This report was prepared as an account of work sponsored by an agency of the United States government. Neither the United States government nor any agency thereof, nor any of their employees, makes any warranty, express or implied, or assumes any legal liability or responsibility for the accuracy, completeness, or usefulness of any information, apparatus, product, or process disclosed, or represents that its use would not infringe privately owned rights. Reference herein to any specific commercial product, process, or service by trade name, trademark, manufacturer, or otherwise does not necessarily constitute or imply its endorsement, recommendation, or favoring by the United States government or any agency thereof. The views and opinions of authors expressed herein do not necessarily state or reflect those of the United States government or any agency thereof.

This report is available at no cost from the National Renewable Energy Laboratory (NREL) at www.nrel.gov/publications.

Available electronically at SciTech Connect http:/www.osti.gov/scitech

Available for a processing fee to U.S. Department of Energy and its contractors, in paper, from:

U.S. Department of Energy

Office of Scientific and Technical Information

P.O. Box 62

Oak Ridge, TN 37831-0062

OSTI http://www.osti.gov

Phone: 865.576.8401

Fax: 865.576.5728

Email: reports@osti.gov

Available for sale to the public, in paper, from:

U.S. Department of Commerce

National Technical Information Service

5301 Shawnee Road

Alexandria, VA 22312

NTIS http://www.ntis.gov

Phone: 800.553 .6847 or 703.605 .6000

Fax: 703.605.6900

Email: orders@ntis.gov 


\section{Acknowledgments}

Funding for this project was provided by Archer Daniels Midland Company, Cargill, Inc., Growth Energy, Illinois Corn Marketing Board, Illinois Renewable Fuels Association, and Poet, LLC. 


\section{List of Acronyms}

ASTM

DCA

EPA

Exx

FFV

GM

IVD

$\mathrm{kg}$

$\mathrm{L}$

$\operatorname{mass} \%$

$\mathrm{mg}$

$\mathrm{mL}$

ppm

$\mathrm{r}$

$\mathrm{R}$

vol $\%$

$\mathrm{wt} \%$
ASTM International

deposit control additive

U.S. Environmental Protection Agency

percent of ethanol in gasoline, where $\mathrm{xx}$ is the

percent by volume of ethanol in gasoline

flex-fuel vehicle

General Motors Corporation

intake valve deposits

kilogram

liter

percent by mass

milligram

milliliter

parts per million by mass or milligrams per

kilogram

ASTM test method repeatability

ASTM test method reproducibility

percent by volume

percent by weight 


\section{Executive Summary}

This report reviews the chemistry of sulfate salts dissolved in ethanol and gasoline, potential sources of sulfate salts in ethanol and gasoline, the history of consumer vehicle issues with sulfate salt deposits in the early 2000s, and the corresponding changes to the denatured fuel ethanol specification. Recommendations for future research are provided. During a period of rapid market expansion in 2003-05, issues were reported with vehicles running on E10 provided by certain suppliers in some markets. It was commonly believed that these vehicle problems were caused by sulfate salts precipitating from the fuel. Investigators identified sodium sulfate, and in one case also ammonium sulfate, as the predominant salts found in the engines. Several stakeholders believed the issue was excess sulfate ions in the ethanol portion of the E10, and in 2005 the ASTM International specification for ethanol (D4806) was modified to include a 4-part per million (ppm) limit on sulfate ions. While there have been no further reports of consumer vehicle issues, the recently approved increase of ethanol in gasoline from 10 to 15 volume percent has resulted in renewed interest in the sulfate ion concentration in fuel ethanol.

There are likely several sources for sulfate ions in denatured fuel ethanol. One possible source identified is the oxidation of sulfite ions to sulfate ions. Sulfite $\left(\mathrm{SO}_{3}{ }^{-2}\right)$ or sulfur dioxide $\left(\mathrm{SO}_{2}\right)$ can be added upstream of distillation in the ethanol production process, and can be created as a fermentation metabolic product of some yeast strains. Experimental evidence demonstrates that the distillation process will not remove sulfite, which can distill with, and be concentrated in, the fuel ethanol product. Ethanol producers believe that sulfate and sodium do not distill with the ethanol but remain with the stillage. Fuel blenders have observed that sulfate concentrations in ethanol tanks can increase over time because of the oxidation of sulfite.

Most sources on the solubility of various sulfite and sulfate salts in ethanol indicate that solubility is below $100 \mathrm{ppm}$. However, there is experimental evidence that sodium sulfate solubility in ethanol is particularly low, i.e., no more than $0.3 \mathrm{ppm}$, and likely much lower. A large producer shared sulfate ion analytical data acquired by an independent testing laboratory on over 1,600 ethanol samples acquired from multiple production facilities over 5 years. Sulfate ion was below detection in $48 \%$ of the samples. A significant number of samples showed sulfate up to $1 \mathrm{ppm}$, and about $4 \%$ were over $2 \mathrm{ppm}$. Given that sodium sulfate does not appear to be soluble at more than about $0.3 \mathrm{ppm}$, this implies that the cation present in these samples is not sodium. The charge balancing cation is likely $\mathrm{H}^{+}$in our opinion.

There are also numerous potential sources of sulfite, sulfate, and sodium ions in a petroleum refinery that could contaminate hydrocarbon fuel products. Additionally, products stored in the presence of tank water bottoms may also be exposed to sulfite, sulfate, sodium, and other salt ions. While no specific incidents of product contamination were documented in the open literature, to assert that the hydrocarbon portion of ethanol blends is completely free of sodium, sulfate, and sulfite ions does not seem reasonable.

Examination of historical information on the consumer vehicle issues that occurred in 20042005 reveals consumer complaints about poor driveability, rough idle, slow startup, misfire, and stuck fuel injectors, especially in colder weather in Milwaukee, Wisconsin. Based on an investigation of injector sticking issues, General Motors proposed that the problem came from the build-up of sulfate salt inside the injectors in warmer months, which led to sticking in colder 
months. However, efforts to recreate the problem in a vehicle control fleet were not successful. Investigations by others indicated that sulfate ions in ethanol played a role, but were likely not the only factor. A source of sodium and in one case ammonium ions, was also required for the formation of the observed insoluble salts and no source was ever identified. Additionally, poorly understood fuel additive issues were mentioned by many stakeholders that we interviewed, and in particular that ammonium ion could have been a contaminant in a gasoline detergent additive.

The path forward to avoiding future issues with sulfate salts as ethanol levels in gasoline are increased is to develop a better fundamental understanding of sulfite and sulfate ion chemistry, as well as the chemistry of the charge balancing cations in these fluids. Potential sources of cations for formation of less soluble sulfate salts, particularly sodium and ammonium, in additives and in the hydrocarbon blendstock need to be identified. Analytical methods for sulfite and sulfate in ethanol, hydrocarbons, and gasoline containing ethanol, and for sodium and other potential cations in blendstocks and fuels need to be developed or improved to make lower detection limits and greater precision possible. Using these new methods, measurements of sulfite and sulfate salt solubility over a range of temperatures in denatured ethanol, hydrocarbon blendstock, and finished gasolines containing ethanol can be made. A more detailed understanding of the fate of sulfite, sulfate, and sodium in ethanol beer distillation should be developed. ${ }^{1}$ The factors affecting the rate of sulfite oxidation to sulfate in denatured fuel ethanol should be studied, and perhaps ways to limit these processes can be developed.

\footnotetext{
${ }^{1}$ Ethanol "beer" is the product of fermentation that is a mixture of water, ethanol (roughly 15 vol\%) and other materials that are distilled to produce $95 \%$ ethanol that is subsequently dewatered and denatured.
} 


\section{Table of Contents}

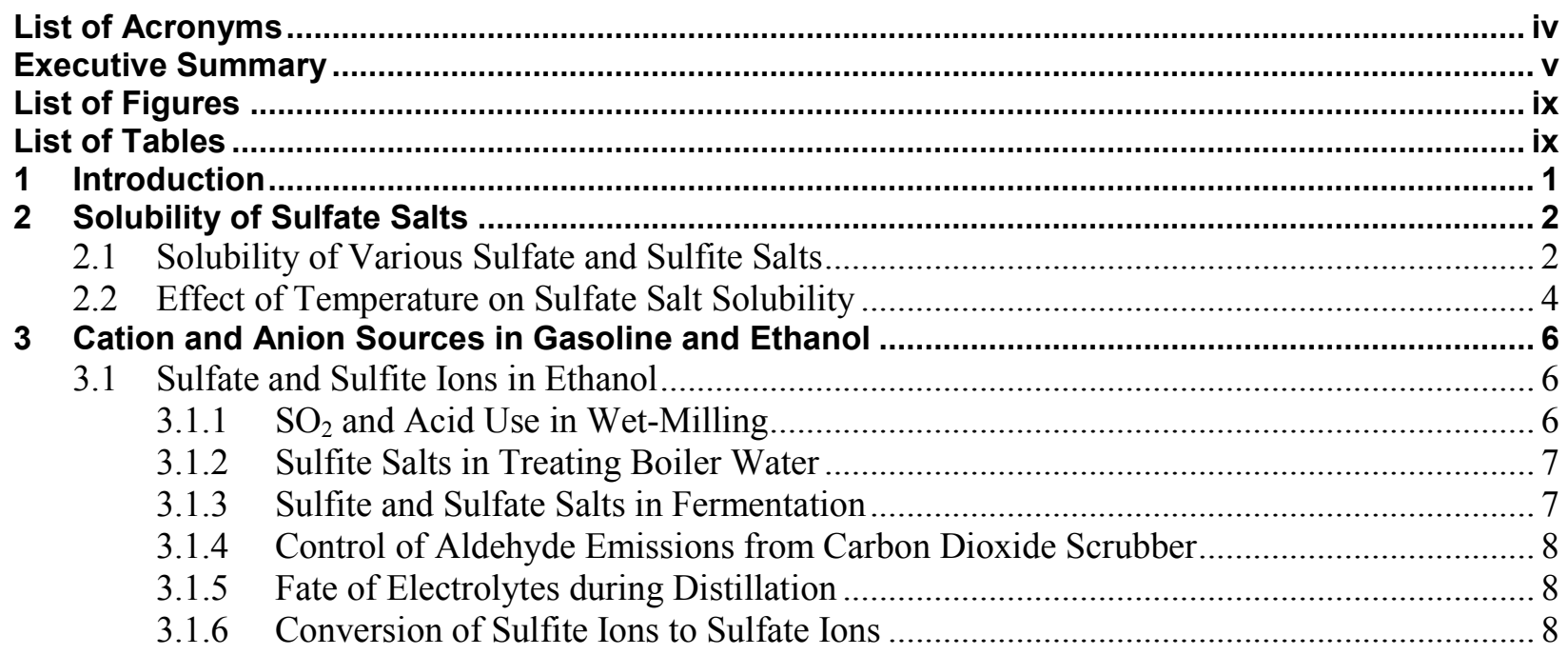

3.2 Anions and Cations in Hydrocarbon Gasoline Components ................................................. 9

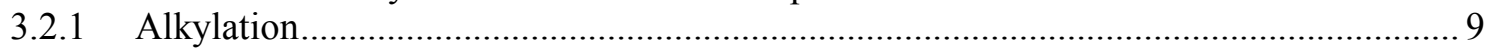

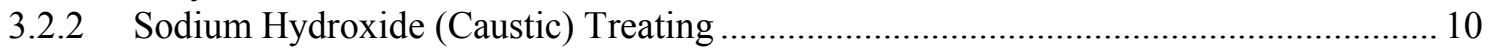

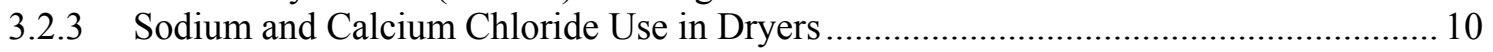

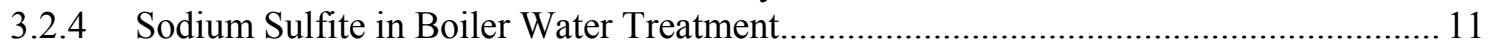

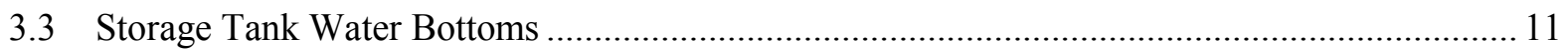

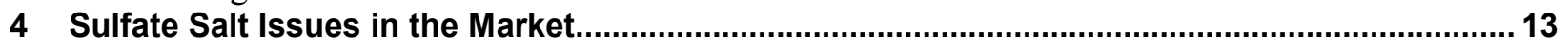

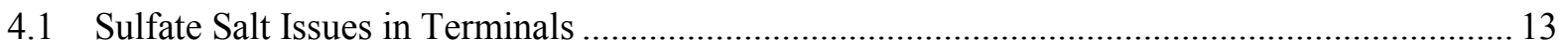

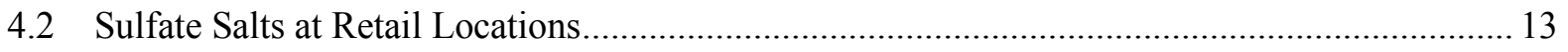

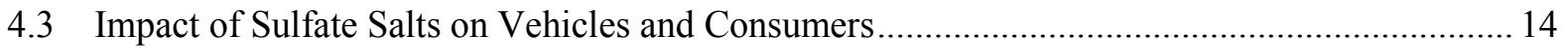

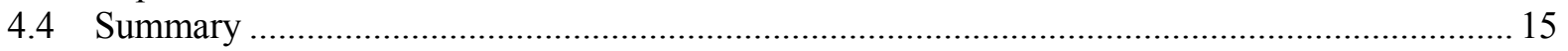

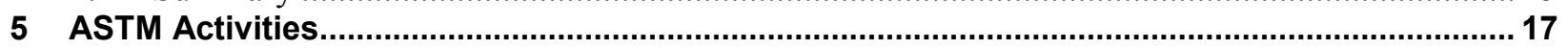

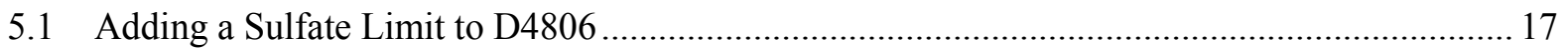

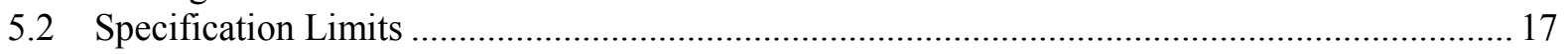

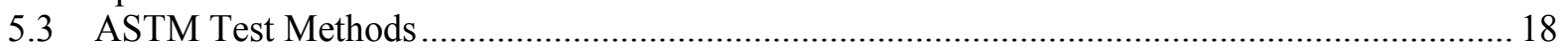

5.3.1 D7318 Standard Test Method for Existent Inorganic Sulfate in Ethanol by

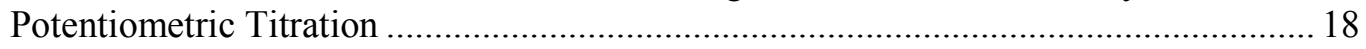

5.3.2 D7319 Standard Test Method for Determination of Existent and Potential Sulfate and Inorganic Chloride in Fuel Ethanol and Butanol by Direct Injection Suppressed Ion Chromatography.....

5.3.3 D7328 Standard Test Method for Determination of Existent and Potential Inorganic Sulfate and Total Inorganic Chloride in Fuel Ethanol by Ion Chromatography Using

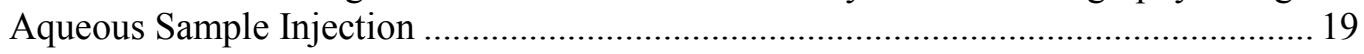

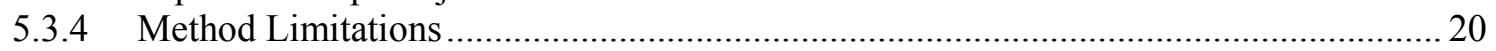

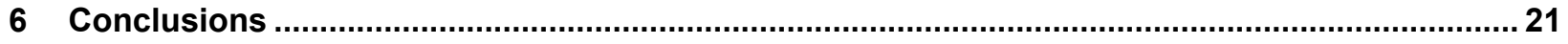

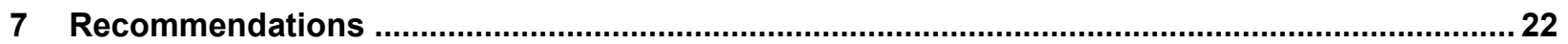

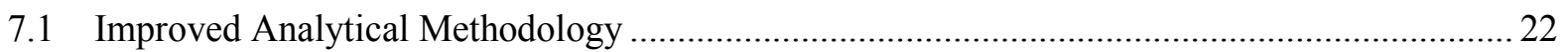

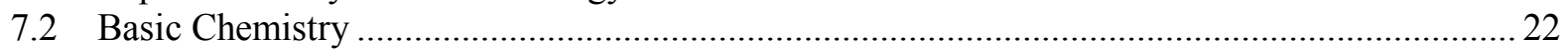

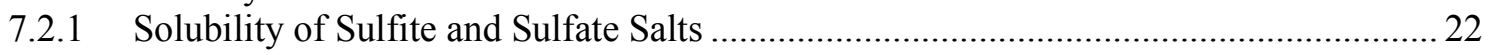

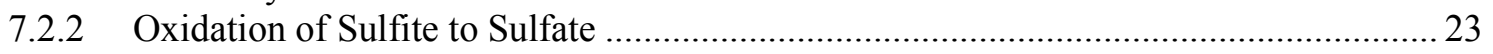

7.3 Inorganic Ions in Hydrocarbon Blendstocks and Additives .................................................. 23

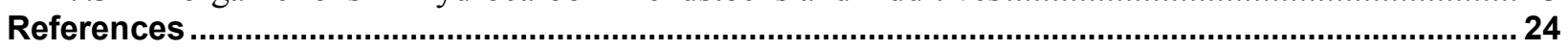




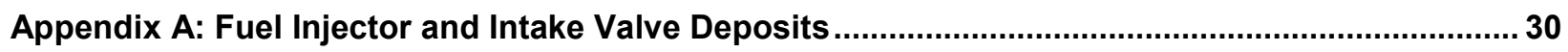

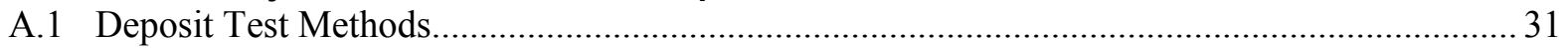

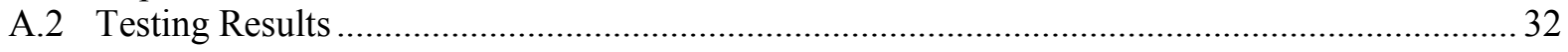

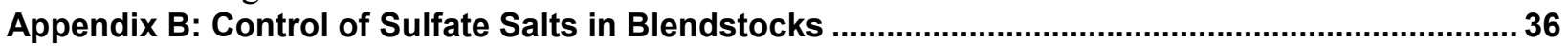

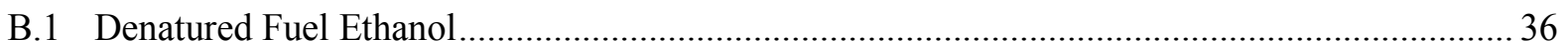

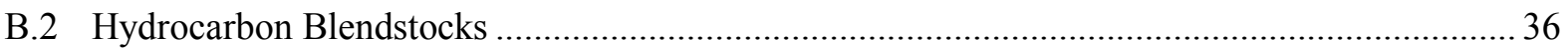




\section{List of Figures}

Figure 1. Solubility of sodium sulfate in ethanol-water solutions at $25^{\circ} \mathrm{C}$

Figure 2. Sodium sulfate solubility in E85 (Keuken 2014). The red line represents the current U.S. sulfate standard, $4 \mathrm{ppm}$ in denatured fuel ethanol, which equates to $3.4 \mathrm{ppm}$ in E85....................... 4

Figure 3. Histogram of E10 blend water content from 2011 summer and winter gasoline quality surveys (Alliance of Automobile Manufacturers 2011).

Figure 4. Solubility of sulfate salts in water at various temperatures, data from Dean (1985)................... 5

Figure 5. Histogram of sulfate ion content for over 1,600 denatured fuel ethanol samples provided by a

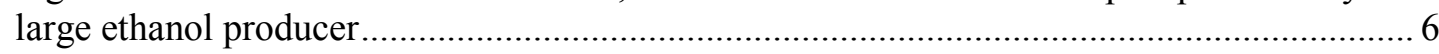

Figure 6. Effect of $\mathrm{pH}$ on species present in aqueous solution after dissolution of $\mathrm{SO}_{2}$ (after Guido [2016])

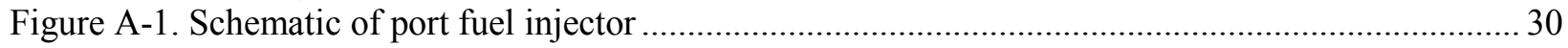

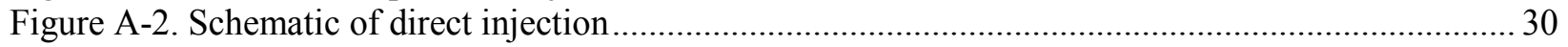

\section{List of Tables}

Table 1. Solubility in $\mathrm{g} / 100 \mathrm{~mL}$ of Various Salts in Water and Ethanol at $20^{\circ} \mathrm{C}$.................................... 2

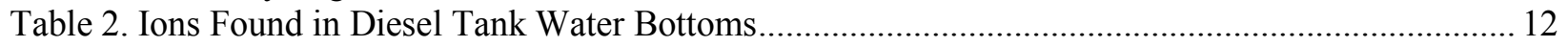

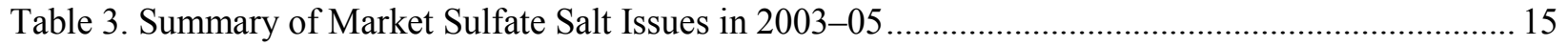

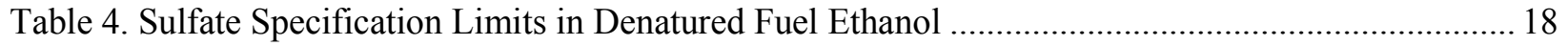

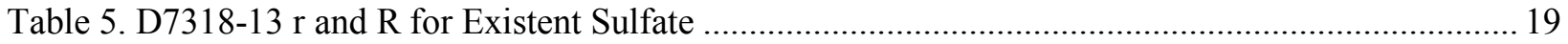

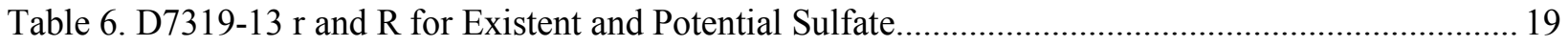

Table 7. D7328-13 r and R for Existent and Potential Sulfate............................................................. 20

Table A-1. ASTM Standards for Test Cycles for Comparing Effect of Fuels and Deposit Control

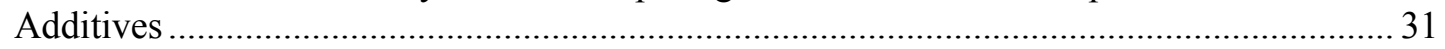

Table A-2. Summary of IVD Deposit Testing on a Chevrolet FFV using E85 and Conventional Gasoline with various Additive Chemistries and Treat Rates.............................................................. 34 


\section{Introduction}

The use of ethanol in gasoline in the United States began as a demonstration fuel in the mid1970s in the Midwest (Bechtold 1987). Only a decade later, larger volumes (up to about 2 billion gallons) of ethanol were blended into gasoline. The decline of methyl tert-butyl ether in gasoline, a direct competitor to ethanol, coupled with various legislative actions (e.g., Crude Oil Windfall Profits Tax 1980, United States Environmental Protection Agency 2016a), led to rapid growth in fuel ethanol production and blending. The fuel ethanol market was 2 billion gallons through 2002 , doubling to $\sim 4$ billion gallons by 2006 . A sustained period of rapid growth came on the heels of the Renewable Fuel Standard, reaching 12 billion gallons by 2010 and 14.7 billion gallons in 2015 (the last year of complete data) (Renewable Fuels Association 2016). Today, nearly all gasoline sold in the United States contains 10 volume percent (vol\%) ethanol (E10).

The growth of the fuel ethanol market was not without challenges. During a period of rapid market expansion in 2004-05, issues were reported with vehicles running on E10 provided by certain suppliers in some markets. Oil companies and vehicle manufacturers have attributed these vehicle problems to sulfate salts from the fuel. Investigators identified sodium sulfate and, in one case, ammonium sulfate as the predominate salts deposited in the engine fuel injectors. Several stakeholders believed the issue was excess sulfate ion in the ethanol portion of the E10. The vehicle problems were virtually eliminated when various companies put purchasing specifications in place to limit sulfate ions in ethanol, although other factors may have been changed in this same timeframe. Eventually, the ASTM International (ASTM) specification for ethanol (D4806) included a 4-part per million (ppm) limit on sulfate ions.

While there was evidence implicating sulfate ions in fuel ethanol as a contributing factor, the root cause of the sulfate salts in vehicle engines was never definitively resolved. Other factors such as incompatible or contaminated fuel additives or contaminants from the petroleum-derived blendstock may also have been responsible. In particular, it was hypothesized that the sodium or ammonium cations may not have been present in the ethanol prior to blending with the hydrocarbon blendstock, and the source of these cations was never identified. The 4-ppm sulfate limit was set by mutual agreement based on engineering judgement of the information available at the time. The recent allowable increase of ethanol in gasoline from 10 to $15 \mathrm{vol} \%$ has resulted in renewed interest in the sulfate ion concentration in fuel ethanol. Oil industry representatives have questioned whether the 4-ppm limit on sulfates continues to be protective to the consumer when the ethanol content in gasoline increases by $50 \%$. Ethanol industry representatives question whether an increase from an effective limit of $0.4 \mathrm{ppm}$ to $0.6 \mathrm{ppm}$ in the finished fuel blend is meaningful, and whether consumers might be better served by limits on other contributing factors. This report reviews the chemistry of sulfate salts dissolved in ethanol and gasoline, potential sources of sulfate salts in ethanol and gasoline, a history of the consumer issues in the early 2000 s, the corresponding changes to the denatured fuel ethanol specification, and future research recommendations.

Note that as a part of this work, the much more extensive literature on intake valve deposits and fuel injector deposits not related to sulfate salts was also reviewed. This information is summarized in Appendix A. 


\section{Solubility of Sulfate Salts}

\subsection{Solubility of Various Sulfate and Sulfite Salts}

Salts contain both a cation and an anion, which dissociate when dissolved in polar liquids such as water. Sulfate salts can be highly soluble in water and other polar solvents. Salts are poorly soluble in non-polar liquids such as hydrocarbons, and may exist as undissociated ion pairs in these liquids. Ethanol is in some ways an intermediate case-much less polar than water, but much more polar than hydrocarbons.

The solubilities of various sulfate and sulfite salts in water and ethanol are listed in Table 1 . Solubility is dependent on both the cation and the anion, that is, a given anion such as sulfate can be highly soluble with certain cations $\left(\mathrm{H}^{+}\right.$in the case of sulfuric acid in ethanol, for example) but has very low solubility with other cations $\left(\mathrm{Na}^{+}\right.$for sodium sulfate in ethanol, for example). While all of the salts of interest are relatively soluble in water, they are also commonly stated to be insoluble or very poorly soluble in ethanol. However, the data for solubility in ethanol are not of high quality. For example, several sources indicate that sodium sulfate is insoluble in ethanol, which is defined as less than $0.01 \mathrm{~g} / 100 \mathrm{~mL}$ of ethanol. This level of sodium sulfate is roughly $100 \mathrm{ppm}$, so while poorly soluble, solubility may still be high enough to be relevant for denatured fuel ethanol with a sulfate limit of $4 \mathrm{ppm}$. Very little data on salt solubility in reagent grade ethanol or denatured ethanol meeting ASTM D4806 are available. Luecke and McCormick (2014) found sodium sulfate to be insoluble in reagent grade ethanol denatured with natural gasoline in a study of how salts affect denatured ethanol's electrical conductivity. A review of laboratory notes from that project shows that sodium sulfate solubility was no more than 0.3 ppm, and likely much lower.

A number of studies have investigated sulfate salt solubility in ethanol-water mixtures. In these studies, ethanol is essentially used as a salting agent, causing precipitation of salts out of aqueous solution as the ethanol content increases. Some of the results for sodium sulfate are summarized in Figure 1. The 1950 paper by Vener and Thompson reports a solubility of 0.002 percent by weight (wt $\%)$, or 20 ppm, for a 79\% ethanol solution.

Table 1. Solubility in $\mathrm{g} / 100 \mathrm{~mL}$ of Various Salts in Water and Ethanol at $20^{\circ} \mathrm{C}$

\begin{tabular}{|c|c|c|}
\hline Salt & Water Solubility $^{a}$ & Ethanol Solubility \\
\hline $\mathrm{H}_{2} \mathrm{SO}_{4}$ (sulfuric acid) & Miscible & Miscible \\
\hline$\left(\mathrm{NH}_{4}\right)_{2} \mathrm{SO}_{3}$ & 60.8 & Very low or insoluble $(<0.01)$ \\
\hline$\left(\mathrm{NH}_{4}\right)_{2} \mathrm{SO}_{4}$ & 75.4 & Insoluble $(<0.01)$ \\
\hline $\mathrm{Na}_{2} \mathrm{SO}_{3}$ & $26.1^{b}$ & Very low or insoluble $(<0.01)$ \\
\hline $\mathrm{Na}_{2} \mathrm{SO}_{4}$ & 40.8 & $<0.3 \mathrm{ppm}^{\mathrm{c}}$ \\
\hline $\mathrm{MgSO}_{4}$ & 39.7 & $0.025\left(\right.$ at $\left.15^{\circ} \mathrm{C}\right)$ \\
\hline $\mathrm{CaSO}_{4}$ & 0.264 & Insoluble \\
\hline $\mathrm{SO}_{2}{ }^{\mathrm{d}}$ & 10.65 & 45.9 \\
\hline
\end{tabular}




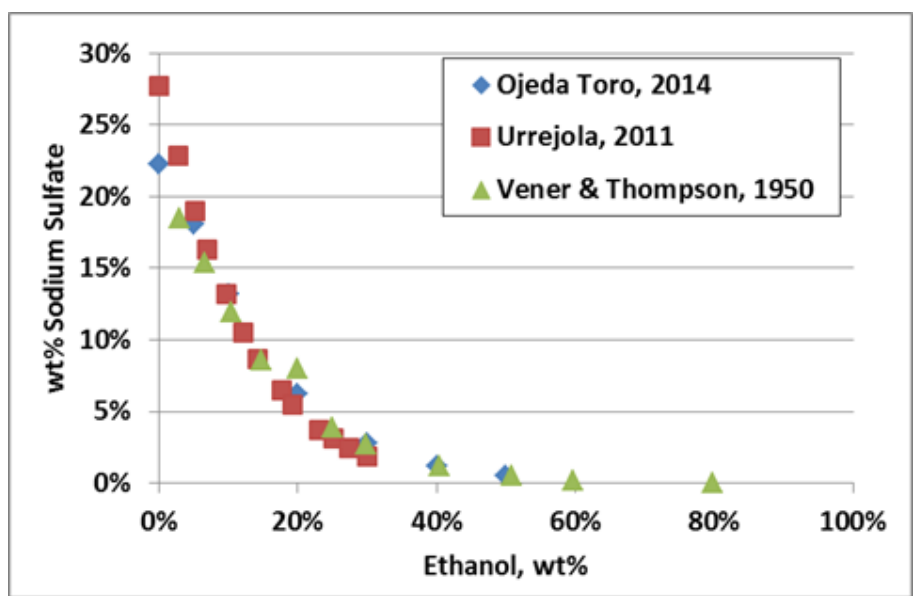

Figure 1. Solubility of sodium sulfate in ethanol-water solutions at $25^{\circ} \mathrm{C}$

Urrejola et al. (2011) has fit solubility measurements of sulfate salts in ethanol-water blends to the following equation, showing the exponential increase in solubility with decreasing ethanol content:

$$
\ln (m)=\ln \left(m_{0}\right)+\sum_{i=1}^{P}\left(A_{i} w_{e}^{i}\right)
$$

where $\mathrm{m}$ is the molality ${ }^{2}$ of the sulfate salt in the ethanol-water mixture, $\mathrm{m}_{0}$ is the molality of the saturated water solution at 0 percent by mass (mass $\%$ ) ethanol, $\mathrm{w}_{\mathrm{e}}$ is the ethanol mass fraction of the salt-free solution, and the $\mathrm{A}_{i}$ are adjustable parameters that are specified for various temperatures and vary depending on whether the cation is copper, potassium, or sodium. There was good agreement between the solubility measurements and the equation, but unfortunately measurements were only made to up to a concentration of about 30 mass $\%$ ethanol. For sodium sulfate at $15^{\circ} \mathrm{C}$, the solubility in water is $0.932 \mathrm{~mol} / \mathrm{kg}(0.13 \mathrm{~kg} / \mathrm{kg}$ water, or $11.5 \mathrm{wt} \%)$, but at 30 mass $\%$ ethanol, the solubility is only $0.074 \mathrm{~mol} / \mathrm{kg}(0.011 \mathrm{~kg} / \mathrm{kg} 30 \mathrm{wt} \%$ ethanol in water or about $1 \mathrm{wt} \%$ ). Extrapolating to $100 \%$ ethanol, the solubility of sodium sulfate is predicted to be about $30 \mathrm{ppm}$, although this is far outside the range of the data used to develop this empirical equation.

There is some evidence that relatively low levels of water in ethanol can have a significant effect on the solubility of sulfate salts in gasoline-ethanol blends: sulfate salt solubility increases with increasing water content in the blend. While the data are not of high quality, water content over 2 vol\% caused a large increase in sodium sulfate solubility in E85 (Figure 2). The lack of effect at $1 \%$ water and lower is likely because of the inability to measure sulfate with high precision using the methods employed. Denatured fuel ethanol meeting the ASTM D4806 standard is required to have less than $1.0 \%$ vol\% water $(1.25$ mass $\%)$. At this level of water content, the effect may not be important for sulfate salt solubility in gasoline blends such as E10 and E15, which have much lower water content than E85. At the upper limit for denatured fuel ethanol of 1.25 mass $\%$ water, E10 and E15 blends would only contain 0.125 and 0.1875 mass\% water, respectively. Gasoline quality survey data show E10 water content to be typically 1,200 ppm (0.12 mass\%, median

\footnotetext{
${ }^{2}$ Number of moles of solute per kilogram of solvent.
} 
value of 780 samples), although there are some samples containing as much as 1,900 ppm (see Figure 3). In no case was the water content high enough to significantly increase sodium sulfate solubility in the fuel.

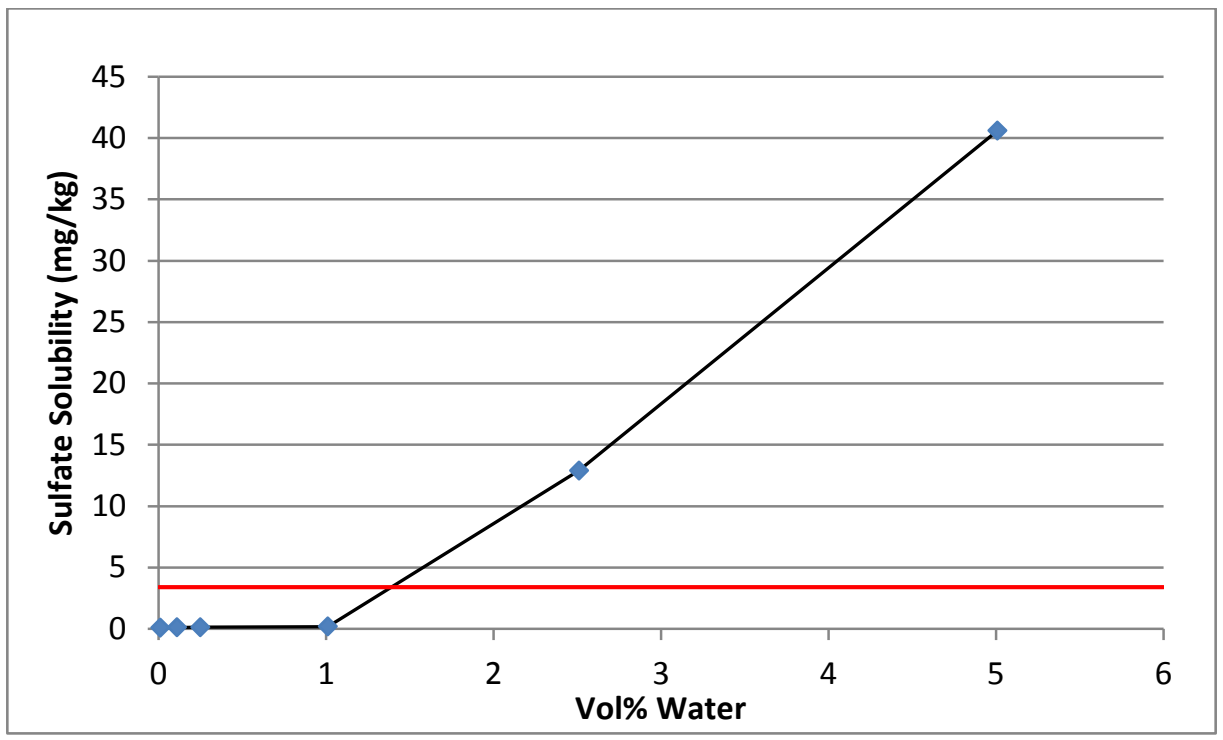

Figure 2. Sodium sulfate solubility in E85 (Keuken 2014). The red line represents the current U.S. sulfate standard, $4 \mathrm{ppm}$ in denatured fuel ethanol, which equates to $3.4 \mathrm{ppm}$ in E85.

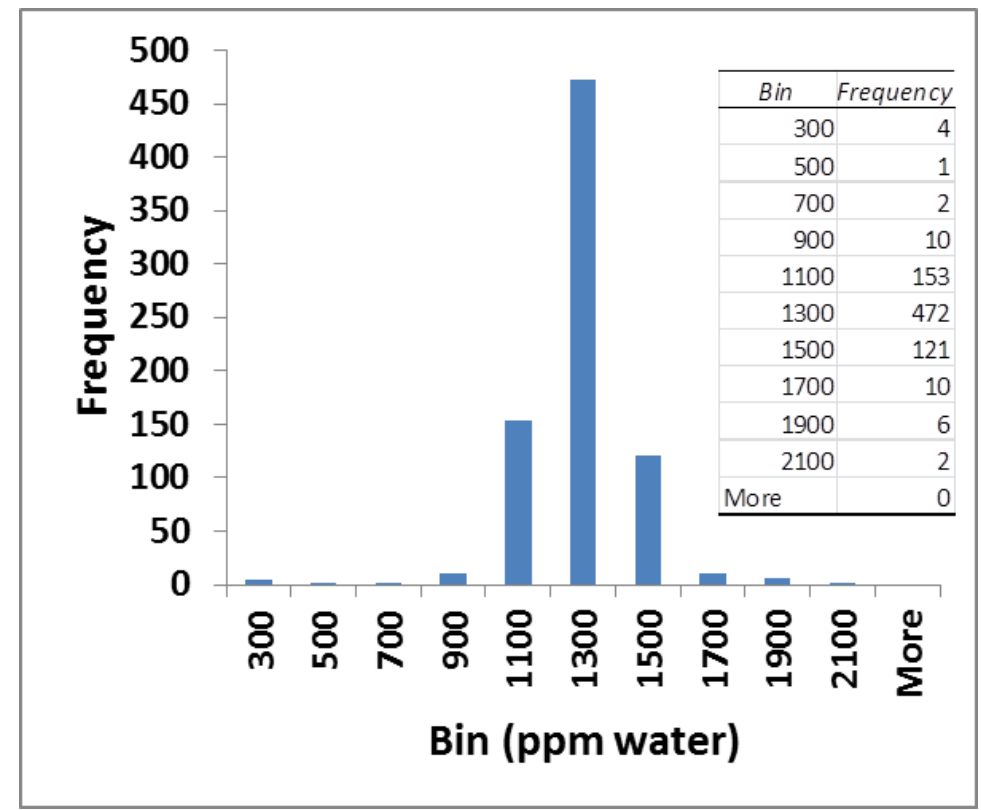

Figure 3. Histogram of E10 blend water content from 2011 summer and winter gasoline quality surveys (Alliance of Automobile Manufacturers 2011)

\subsection{Effect of Temperature on Sulfate Salt Solubility}

The solubility of sodium sulfate $\left(\mathrm{Na}_{2} \mathrm{SO}_{4}\right)$ in water increases as temperature rises up to about $32^{\circ} \mathrm{C}$, and then slightly decreases at higher temperatures (Figure 4). This unusual shaped 
solubility curve is due to a change in the crystalline form of sodium sulfate. At temperatures below $32^{\circ} \mathrm{C}$, solid sodium sulfate exists as a decahydrate, that is, it includes water molecules within its crystalline structure, which increases the stability of the solid form and thus decreases its solubility. Above that temperature, the water is released. Magnesium and calcium sulfate also have hydrate forms with unusual solubility/temperature curves (results for magnesium are shown in Figure 4), while ammonium sulfate solubility increases monotonically with temperature. Ammonium sulfate can combine with other cations to form double salts, leading to even more complex solubility relationships. Thus, though we normally expect solubility to increase with increasing temperature, this does not apply to sulfates in aqueous solutions. Given the very low levels of water present in E10 and presumably also in E15 blends, and given the high affinity of ethanol for water, the hydrated sulfate salts seem unlikely to form.

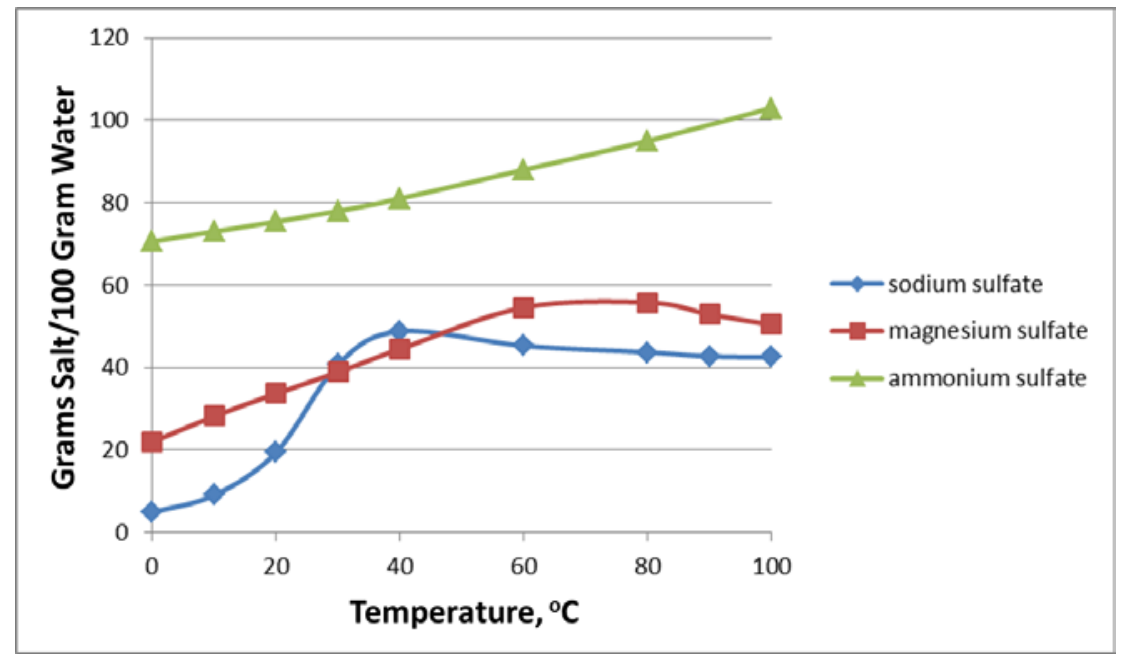

Figure 4. Solubility of sulfate salts in water at various temperatures, data from Dean (1985). 


\section{Cation and Anion Sources in Gasoline and Ethanol}

\subsection{Sulfate and Sulfite Ions in Ethanol}

Sulfate and/or sulfite ions can be found at multiple points in a number of ethanol plants, and sulfate ion can be present at low levels in denatured fuel ethanol from those facilities. For example, a large producer shared sulfate ion analytical data acquired by an independent testing laboratory on over 1,600 ethanol samples acquired from multiple production facilities over 5 years. These data are shown in Figure 5. For $48 \%$ of the samples, the sulfate ion content is below detection, but there are a significant number of samples showing sulfate up to $1 \mathrm{ppm}$, and about $4 \%$ over $2 \mathrm{ppm}$. Given that sodium sulfate does not appear to be soluble at more than about 0.3 ppm, this implies that the cation present in these samples is not sodium. The various uses and sources of sulfite and sulfate ions in ethanol production facilities are described below. Information on removing sulfate salts from ethanol and other blendstocks is presented in Appendix B.

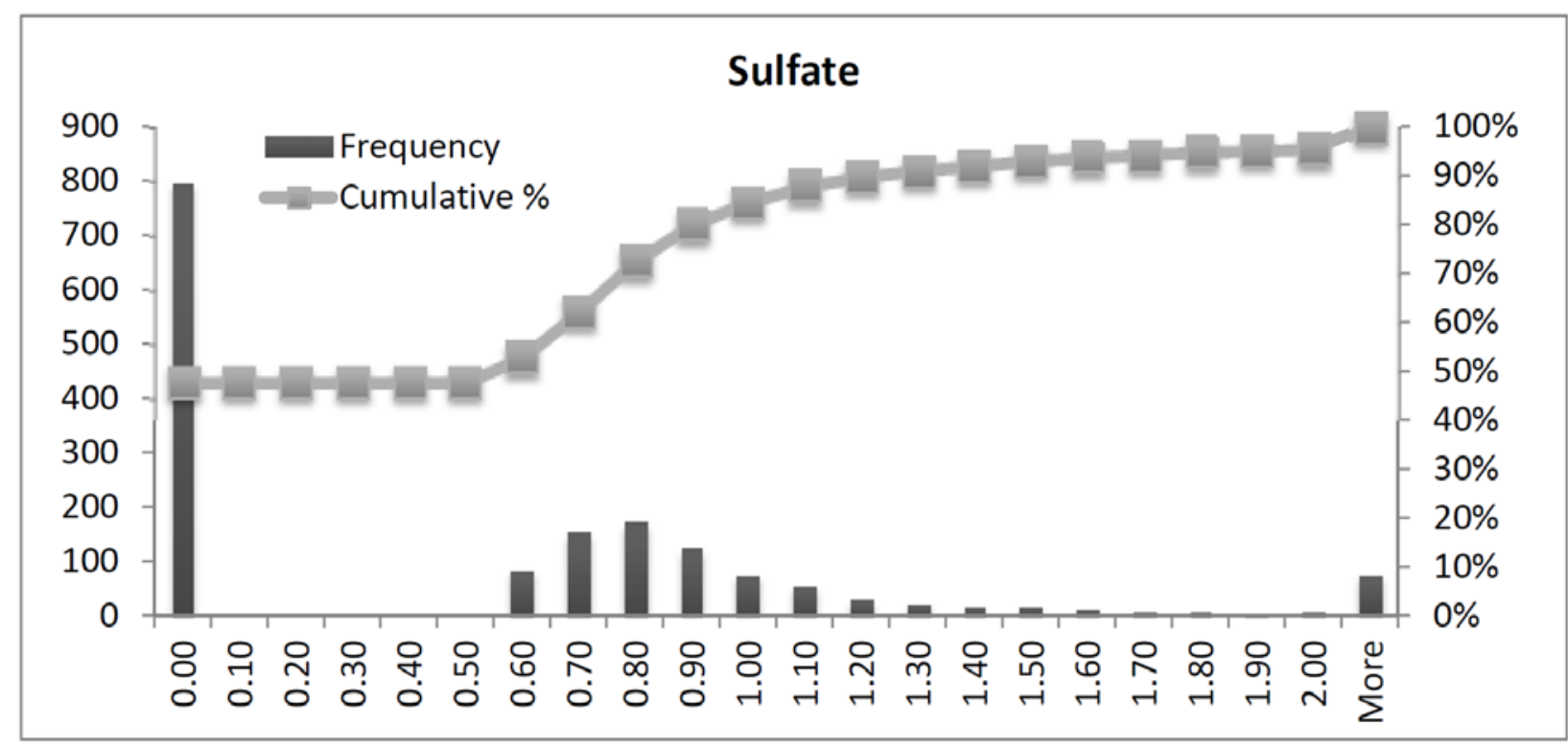

Figure 5. Histogram of sulfate ion content for over 1,600 denatured fuel ethanol samples provided by a large ethanol producer

\subsection{1 $\mathrm{SO}_{2}$ and Acid Use in Wet-Milling}

Steeping of the corn kernels in aqueous solutions of $\mathrm{SO}_{2}$ is required for wet-milling and results in degradation of the kernel structure, allowing recovery of relatively pure starch, protein, and other fractions (Shandera and Jackson 1996, Nalco 2009). $\mathrm{SO}_{2}$ is added at nominally 2,000 ppm, although the actual level will vary with the process design and operation strategy. In aqueous solution, the following reactions of $\mathrm{SO}_{2}$ take place:

$$
\begin{gathered}
\mathrm{SO}_{2 a q}+\mathrm{H}_{2} \mathrm{O}_{l} \leftrightarrow \mathrm{H}_{a q}^{+}+\mathrm{HSO}_{3}{ }^{1-} a q \\
\mathrm{HSO}_{3 a q} \leftrightarrow \mathrm{H}_{a q}^{+}+\mathrm{SO}_{3}{ }^{2-}{ }^{a q} \\
2 \mathrm{HSO}_{3 a q} \leftrightarrow \mathrm{S}_{2} \mathrm{O}_{5}{ }^{2-}{ }_{a q}+\mathrm{H}_{2} \mathrm{O}_{l}
\end{gathered}
$$


At moderately low $\mathrm{pH}$, the equilibrium constant for reaction 3.1-1 is orders of magnitude higher than those for reactions 3.1-2 and 3.1-3 such that the primary species in solution is the bisulfite anion $\mathrm{HSO}_{3}{ }^{1-}$ (Goldberg and Parker 1985). However, at neutral $\mathrm{pH}$ both bisulfite and sulfite will be present (Figure 6). In some cases, sulfite, bisulfite, and their associated hydrogen cations move with the starch into the ethanol fermentation and can end up in the product beer, ${ }^{3}$ ultimately carrying over with the ethanol during distillation (Nalco 2009).

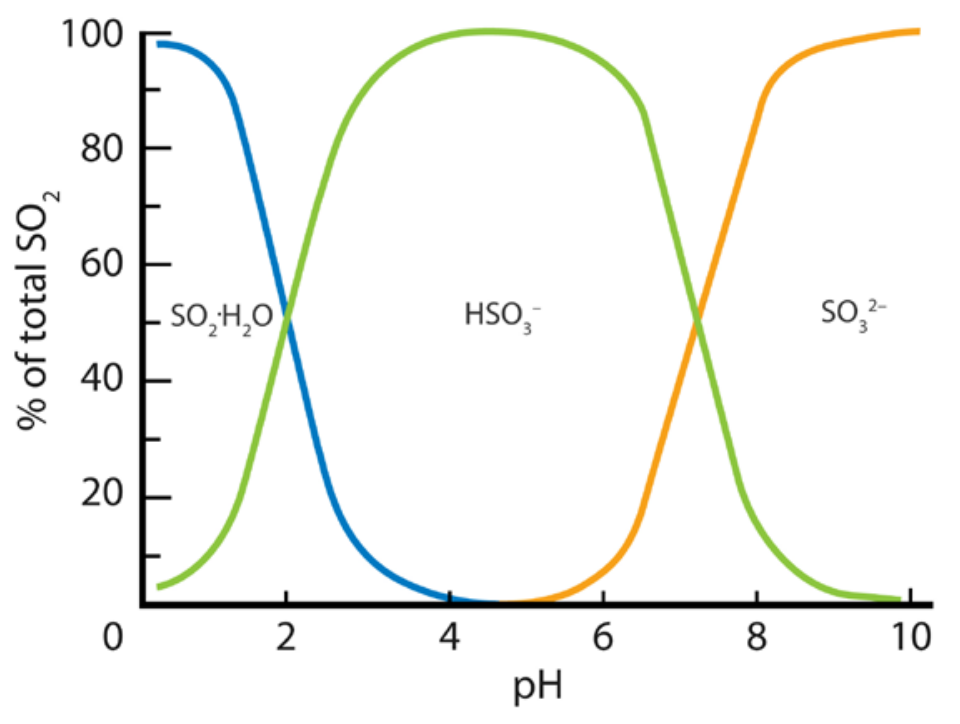

Figure 6. Effect of $\mathrm{pH}$ on species present in aqueous solution after dissolution of $\mathrm{SO}_{2}$ (after Guido [2016]).

\subsubsection{Sulfite Salts in Treating Boiler Water}

Sulfite salts are commonly added to boiler feed water as an oxygen scavenger to prevent corrosion in the steam production system. The salts used include (Zupanovich 2002):

- Sodium sulfite $\left(\mathrm{Na}_{2} \mathrm{SO}_{3}\right)$

- Sodium hydrogen sulfite (or sodium bisulfite) $\left(\mathrm{NaHSO}_{3}\right)$

- Sodium metabisulfite $\left(\mathrm{Na}_{2} \mathrm{~S}_{2} \mathrm{O}_{5}\right)$

- Ammonium sulfite $\left(\left(\mathrm{NH}_{4}\right)_{2} \mathrm{SO}_{3}\right)$.

While boiler feed water may not come in contact with water used in fermentation, if it were to do so, it could be a significant source of sulfite salts.

\subsubsection{Sulfite and Sulfate Salts in Fermentation}

Sulfite can occur naturally as a product of yeast metabolism in fermentation with the level dependent on the yeast strain, fermentation conditions, and the level of sulfur in the plant matter being fermented. It can also be added as an antimicrobial and antioxidant agent (Ilett 1995). Sulfuric acid can be used as a pH control in fermentation tanks (Retka Shill 2016). An ethanol producer who we interviewed noted that not all sulfuric acid supply has the same residual sulfite

\footnotetext{
${ }^{3}$ Ethanol "beer" is the product of fermentation that is a mixture of water, ethanol (roughly 15 vol\%), and other materials that are distilled to produce $95 \%$ ethanol that is subsequently dewatered and denatured.
} 
levels; furthermore, high residual sulfite present in sulfuric acid used in the process can lead to increased levels of sulfate in the ethanol. Ammonium sulfate may be added as a nitrogen source for yeast to enhance fermentation (Sanchez and Cardona 2008).

\subsubsection{Control of Aldehyde Emissions from Carbon Dioxide Scrubber}

Starting in 2006, the U.S. Environmental Protection Agency (EPA) began regulating acetaldehyde emissions from ethanol plants. Aqueous sodium bisulfite is used in the carbon dioxide scrubber to remove the acetaldehyde, which binds to the bisulfite ion to form $\alpha$-hydroxy ethane sulfonate $\left(\mathrm{CH}_{3} \mathrm{CHOHOSO}_{2}{ }^{-}\right)$. The water is recycled into the ethanol process and therefore could be another source of sulfite ions - and ultimately sulfate ions - in the ethanol product. However, this practice was not initiated until well after the 2004-2005 consumer vehicle issues and is not likely to have been the source of sulfate ion contamination at that time.

\subsubsection{Fate of Electrolytes during Distillation}

Based on conversations with ethanol producers and their suppliers, in the final distillation step the sulfate and sodium ions are not expected to distill with the ethanol, but would remain with the bottoms; however, sulfite ions could distill into the finished fuel ethanol. Few technical references validating this statement could be found; however, the idea that sulfite in the fermentation beer will distill with the ethanol appears to be common knowledge in the distilled spirits industry. For example, Zhang and coworkers (2013) distilled a chardonnay (12 vol\% ethanol) containing $176 \mathrm{~mL} / \mathrm{L}$ of sulfite (as $\mathrm{SO}_{2}$ ). The sulfite not only distilled with the ethanol, but was concentrated, reaching $292 \mathrm{mg} / \mathrm{L}$ after the first stage (27 vol\% ethanol) and $654 \mathrm{mg} / \mathrm{L}$ after the second stage ( $69 \mathrm{vol} \%$ ethanol). While these sulfite levels are much higher than sulfite levels found in the fuel ethanol process, the example illustrates the fate of beer sulfite in distillation. Furthermore, a study of the solubility of $\mathrm{SO}_{2}$ in ethanol-water solutions showed that the solubility is four times higher in ethanol than in water (see Table 1, Tokunaga [1974]).

This route is based on the equilibrium of the dissolved $\mathrm{SO}_{2}$ in water at high temperature:

$$
\mathrm{SO}_{2}+\mathrm{H}_{2} \mathrm{O} \leftrightarrow \mathrm{H}_{2} \mathrm{SO}_{3}
$$

At distillation temperatures and high ethanol content (as would occur at the top of the distillation tower), the equilibrium for reaction 3.1-4 shifts to the left and the $\mathrm{SO}_{2}$ vapor is carried over with the ethanol and dissolves in the ethanol upon condensation, reforming the sulfite ion (Edwards et al. 1975). It is possible to imagine a similar mechanism for sulfate $\left(\mathrm{as}_{2} \mathrm{SO}_{4}\right.$ and $\left.\mathrm{SO}_{3}\right)$, but no evidence for this actually occurring was identified. The cation present to balance the charge in this situation is $\mathrm{H}^{+}$, but at the part-per-million levels observed for sulfite and sulfate, this would have no measureable impact on ethanol product acidity.

\subsubsection{Conversion of Sulfite lons to Sulfate lons}

Because it seems clear that sulfite introduced into the fermentation can ultimately end up in the fuel ethanol, it is possible that a source of sulfate may be conversion of sulfite to sulfate under oxidizing conditions.

$$
2 \mathrm{SO}_{3}{ }^{2-}+\mathrm{O}_{2} \rightarrow 2 \mathrm{SO}_{4}{ }^{2-}
$$


Increasing sulfate levels over time have been observed in fuel ethanol samples (Rowe 2006). Sulfite to sulfate conversion can occur in the presence of atmospheric oxygen (Wilkinson et al. 1993). The addition of an oxidizer like dilute hydrogen peroxide can also drive this reaction, and it may also be accelerated at reduced $\mathrm{pH}$. While there is large uncertainty in the cation-dependent sulfite and sulfate salt solubility in ethanol, as shown in Table 1 (because of lack of data at low concentrations), if sulfite is more soluble than sulfate, its oxidation over time could lead to salt precipitation. The potential for sulfite to oxidize to sulfate in denatured fuel ethanol or in ethanol containing gasolines under normal storage and handling conditions may be an important topic for future research as rates of this reaction in the liquid phase and factors affecting it are essentially unknown.

\subsection{Anions and Cations in Hydrocarbon Gasoline Components}

Several of our interview subjects believed that all sulfate ions in finished gasoline containing ethanol came from the ethanol. Others believed that sulfate ions could also come from the hydrocarbon blendstock used in the finished fuel, though there is little or no public data on sulfate ions in the hydrocarbon portion of the blend to support this assertion. This review did not reveal any specific evidence for contamination of the petroleum refinery-derived blendstocks with sulfate or other inorganic ions as a factor in the sulfate salt engine issues in the 2004-05 time frame. However, sulfuric acid, sodium hydroxide, and chloride salts are commonly used in refineries. Their use and the potential to contaminate finished products are discussed below. Additionally, hydrocarbon fuels and blendstocks are frequently stored in tanks that may contain water bottoms, which could also be a source of salt contamination.

\subsubsection{Alkylation}

The alkylation unit in a petroleum refinery reacts isobutene with $\mathrm{C}_{3}$ to $\mathrm{C}_{5}$ olefins (most commonly butenes) to produce primarily trimethyl pentanes. The product stream, known as alkylate, makes up as much as $15 \%$ of the gasoline blendstock pool in the United States and is highly valued because of its relatively high research octane number (93-97), low Reid vapor pressure, the absence of aromatics and olefins, and lack of impurities such as sulfur. The reaction is catalyzed by either concentrated sulfuric acid or hydrofluoric acid. While there are significant process chemistry and engineering advantages to the hydrofluoric acid process, in recent years the sulfuric acid process has become more common because of potential safety issues with the large-scale use of hydrofluoric acid (Albright 2009).

The sulfuric acid catalyzed reaction takes place in a two-phase dispersion of acid and hydrocarbon with complex chemistry and a complex physicochemical sequence of events (Albright 2003). Mono-alkyl sulfate anions, which are more soluble in the acid phase, and neutral di-alkyl sulfate compounds, which are more soluble in the hydrocarbon product, are formed as intermediates in the reaction. To remove these intermediates from the product, it is common to use a sulfuric acid wash followed by a caustic water wash (Kranz 2008). The sulfuric acid wash removes the acid-soluble mono-alkyl sulfate and converts the di-alkyl sulfate to the more acid-soluble mono form. The caustic water wash neutralizes and removes free acids and remaining mono-alkyl sulfate anions, and hydrolyzes remaining di-alkyl sulfates so that they are also removed. The product is then sent to a distillation tower where unreacted and intermediate olefins are removed and recycled. Under some conditions, sulfuric acid can oxidize the product trimethyl pentanes producing water and $\mathrm{SO}_{2}$, and larger isoparaffins that are less desirable than 
trimethyl pentanes (am Ende and Albright 1994). The sulfuric acid used in the process is regenerated and recycled and may contain impurities such as $\mathrm{SO}_{2}$ and other process-derived contaminants.

We could identify no published information on the potential for the alkylate product to be contaminated with sulfate ions, $\mathrm{SO}_{2}$, or sodium cations from the caustic wash. Nevertheless, a process upset or other uncontrolled operation would have the potential to lead to a product contaminated with any of these materials.

\subsubsection{Sodium Hydroxide (Caustic) Treating}

As noted above, a caustic water wash is used in alkylate cleanup, and caustic solutions are used in other parts of the refinery. In particular a caustic wash can be used to remove naphthenic acids and phenols, as well as reduced organosulfur compounds (mercaptans) and $\mathrm{H}_{2} \mathrm{~S}$. Scrubbing to remove $\mathrm{H}_{2} \mathrm{~S}$ involves the following reaction sequence:

$$
\begin{aligned}
\mathrm{H}_{2} \mathrm{~S}_{a q}+\mathrm{NaOH}_{a q} & \rightarrow \mathrm{NaHS}_{a q}+\mathrm{H}_{2} \mathrm{O} \\
\mathrm{NaHS}_{a q}+\mathrm{NaOH}_{a q} & \rightarrow \mathrm{Na}_{2} \mathrm{~S}_{a q}+\mathrm{H}_{2} \mathrm{O}
\end{aligned}
$$

Sodium bisulfide (NaHS) can be sold, and so is the target product (Mamrosh et al. 2008).

The chemistry for removal of organosulfur compounds involves formation of a sodium mercaptide that is soluble in the caustic solution, followed by oxidation to a disulfide, which can be removed and recycled to a hydrotreater (Sullivan 2004).

$$
\begin{gathered}
\mathrm{RSH}+\mathrm{NaOH}_{a q} \rightarrow \mathrm{NaSR}_{a q}+\mathrm{H}_{2} \mathrm{O} \\
\mathrm{NaSR}_{a q}+1 / 4 \mathrm{O}_{2}+1 / 2 \mathrm{H}_{2} \mathrm{O} \rightarrow \mathrm{NaOH}_{a q}+1 / 2 \mathrm{RSSR}
\end{gathered}
$$

As noted above for alkylation, the complexity of these processes suggests the possibility that outof-control operation could lead to products containing sodium cations. However, we were unable to identify any reports of this actually happening.

\subsubsection{Sodium and Calcium Chloride Use in Dryers}

Steam is used in refineries to strip out impurities as well as more-volatile hydrocarbons from less-volatile streams. Additionally, as noted above, caustic water washes are common in refining. Therefore, hydrocarbon streams are typically saturated with water at elevated temperatures, and this water comes out of solution as these products are cooled. The free water formed can cause the formation of haze in the product, and may also contribute to corrosion. Salt dryers are used in refining to remove this water. Originally, these dryers used rock salt (sodium chloride, or $\mathrm{NaCl}$ ) which removed free water, and many refineries may still use $\mathrm{NaCl}$. Over the past couple of decades, calcium chloride $\left(\mathrm{CaCl}_{2}\right)$ dyers may have become more common because the $\mathrm{CaCl}_{2}$ can remove both free and dissolved water (Barnett 1996).

Contamination of diesel fuel with sodium, potentially originating from salt dryers, has been proposed as a factor in recent incidents of diesel filter plugging and injector fouling (Schwab et al. 2010, Barker et al. 2013). While this does not represent a direct route to contamination of 
gasoline with $\mathrm{NaCl}$, there are situations where gasoline or denatured fuel ethanol can come into contact with diesel fuel, for example in transport trucks that have not been properly cleaned.

\subsubsection{Sodium Sulfite in Boiler Water Treatment}

Sulfite salts are commonly added to boiler feed water as an oxygen scavenger to prevent corrosion in the steam production system. The salts used include (Zupanovich 2002):

- $\quad$ Sodium sulfite $\left(\mathrm{Na}_{2} \mathrm{SO}_{3}\right)$

- Sodium hydrogen sulfite (or sodium bisulfite) $\left(\mathrm{NaHSO}_{3}\right)$

- Sodium metabisulfite $\left(\mathrm{Na}_{2} \mathrm{~S}_{2} \mathrm{O}_{5}\right)$

- Ammonium sulfite $\left(\left(\mathrm{NH}_{4}\right)_{2} \mathrm{SO}_{3}\right.$.

Steam stripping is commonly used in petroleum refining processes and may be a potential route for product contamination with sulfite or sulfate salts.

\subsection{Storage Tank Water Bottoms}

A small amount of water can be dissolved in hydrocarbon fuels. When the hydrocarbons are saturated with water, any additional water will form a second phase in the system. The separate water phase is a fuel contaminant. This water phase is normally allowed to settle to the bottom in a hydrocarbon storage tank. The origin of water in storage tanks comes through many routes: undissolved water may have been present in the fuel received, or it may enter the tank through damaged seals, gaskets, and equipment, and through condensation from ambient air during temperature swings. All hydrocarbon tanks contain some amount of undissolved water-it is simply impossible to keep a tank completely dry (Steel Tank Institute 2006).

The EPA recently published a report on potential sources of corrosion in diesel underground storage tanks (United States Environmental Protection Agency 2016b). While the report was focused on tanks containing diesel fuel, the report included analysis of the ions present in water bottoms in the tanks (Table 2). On average, the sodium cation was found in the highest concentration in the water bottoms. For anions, chloride anions were found in the highest concentrations in these samples, and the second-most common anion was sulfate, though at significantly lower levels than chloride. The observation of fluoride anions may be an indication that acids, including hydrofluoric acid and sulfuric acid, used in alkylation units can be present in refinery products at low levels.

In today's ethanol market where nearly all gasoline sold is E10, both the E10 blend and ethanol are kept as dry as possible to avoid a separate water phase. However, the hydrocarbon blendstock may have been in contact with water through the entire distribution system. Prior to the widespread use of E10, much less care was taken to avoid water contact with gasoline, and a water bottom was common in every gasoline storage tank. Water-soluble salts would have been concentrated in these tank water bottoms. In the 2004-05 timeframe, when sulfate salt issues were occurring in the market, ethanol was not commonly used year-round. The seasonal switch from summer, hydrocarbon-only gasoline to winter gasoline containing ethanol may have presented an opportunity for contamination of the fuel with salts from water bottoms (also the similar situation of ethanol blends being used for the first time in a new market). Compared to the summertime hydrocarbon-only gasoline, winter E10 gasoline can dissolve more water, and 
any water and associated ions entrained in the hydrocarbon blendstock or in the water bottoms of a retail gasoline storage tank would easily be taken up by the E10 blend.

Table 2. lons Found in Diesel Tank Water Bottoms

\begin{tabular}{llll}
\hline Ion & $\begin{array}{l}\text { Minimum, } \\
\text { ppm }\end{array}$ & $\begin{array}{l}\text { Median, } \\
\text { ppm }\end{array}$ & $\begin{array}{l}\text { Maximum, } \\
\text { ppm }\end{array}$ \\
\hline Fluoride & 0.13 & 20.7 & 118 \\
Chloride & 2.3 & 1,920 & 3,468 \\
Nitrate & 0.13 & 0.14 & 79 \\
Sulfate & 1.7 & 83 & 358 \\
Sodium & 176 & 3,120 & 4,687 \\
Ammonium & 0.14 & 14 & 404 \\
Potassium & 0.14 & 23 & 1,112 \\
Magnesium & 0.14 & 42 & 627 \\
Calcium & 0.14 & 99 & 399 \\
\hline
\end{tabular}




\section{Sulfate Salt Issues in the Market}

The discussion in Sections 4 and 5 is based on stakeholder interviews as well as presentations and other documents available to us as ASTM members or supplied to us by the study sponsors. The presentations and documents are from ASTM committee meetings and other private meetings held from 2004 through 2009; therefore, we cannot cite them directly nor can we state specific presenter or company names.

Starting around 2003, issues were reported in some markets with terminal filter and turbine meter clogging, as well as retail dispenser filter clogging. The problems did not affect all fuel blenders or marketers. In late 2004, consumers reported problems with vehicles running on E10, although the problems seemed to be limited to E10 provided by certain suppliers in some markets. Not all models of vehicles appear to have been affected equally. In 2003, the fuel ethanol market was approximately 2.81 billion gallons (Renewable Fuels Association 2016), with about half the fuel ethanol production coming from wet mills and half coming from dry mills.

\subsection{Sulfate Salt Issues in Terminals}

A gasoline marketer reported market problems in bulk storage terminals in Chicago and Milwaukee in 2003-04 where turbine meters used with E10 were coated with a white solid. The problem was not immediately tied to fuel ethanol and was not a major disruption to operations. Subsequent investigation by the gasoline marketer identified sodium and ammonium sulfates as the main components of the white solid. An investigation determined the problem was caused by a gasoline detergent additive interacting with sulfate in denatured fuel ethanol. The interaction of sulfate from ethanol with an additive component was brought up in many of the documents reviewed and in most of the interviews conducted for this project. The term "interaction" is intentionally vague on our part because we were not able to learn any of the details of exactly what this interaction was or on the identity of the additive. Possible modes of interaction include that the additive contained a cation that formed a very low solubility salt with sulfate anions, or alternatively, extremely small particles of a salt may have already formed and the additive somehow caused them to flocculate and clog filters. There may be other explanations.

\subsection{Sulfate Salts at Retail Locations}

There were reports of retail station filter clogging in six different areas/cities (St. Louis; Los Angeles; Roseville, Minnesota; Pacific Northwest; Milwaukee, Wisconsin; and Chicago/Decatur, Illinois) between March 2003 and December 2004. The problems manifested as the need for increased frequency of filter changes at the stations. A normal filter change interval might be several months, and as the problem developed, filter change intervals decreased dramatically to weeks or less. One fuel marketer reported problems were always found in locations with ethanol in the gasoline. Filter forensic analysis showed high levels of sodium sulfate. Working with the ethanol industry, this fuel marketer determined ethanol from wet mills was more frequently involved in filter plugging than ethanol from dry mills. Note that ethanol from wet mills made up roughly half of ethanol production in 2003-04 compared to perhaps $10 \%$ today. 
The same fuel marketer also considered whether additives could solve the problem, as frequent filter changes at stations were not a sustainable solution. A company-led investigation suggested that a gasoline detergent additive was interacting with sulfate salts to form an insoluble precipitate. Other fuel additives could mitigate this issue; however, the company raised concerns about the potential to pass the sulfate salts through the filters and on to the consumer. They reported that changing ethanol suppliers in one market and an additive reformulation in two other markets resolved their precipitation problem.

In a similar timeframe, a second fuel marketer reported an increased rate of filter changing at retail stations from every six months to every two to three weeks in areas of the upper Midwest. The solids in the filters were determined to be a combination of sodium and ammonium sulfate salts. Further internal investigation suggested a gasoline additive was interacting with sulfate anions in the ethanol, as was also determined to be the problem by this marketer at the terminal level. Retained samples of ethanol and gasoline were analyzed, and the problem was attributed to relatively high sulfate concentrations (greater than $8 \mathrm{ppm}$ ) in the ethanol. They reported that no sulfate was found in the gasoline, although the analytical method and detection limits were not provided. Other major gasoline marketers in these areas did not report problems with gasoline containing ethanol.

An additive manufacturer also investigated filter plugging in gasoline-ethanol blends. In-house testing by this company revealed certain detergent additive chemistries contributed to the problem. They reported that switching from a competitor additive to a different additive chemistry eliminated the problem for a fuel marketer.

None of the other additive companies interviewed provided an explanation of the cause of the precipitates. Each company had a differing view of the problem at the time. One company postulated that it was due to dissolved residual sulfite from the ethanol production oxidizing to sulfate and precipitating as the product moved through the distribution system and was exposed to sodium and other cations. A second additive company believed the issue was more likely high sulfate in ethanol and not an additive issue. This company also noted that if the presence of additives was found in the precipitate, it was not because the additive had caused the problem, but because it was a co-precipitate. A third additive company believed the problem coincided with a new additive technology.

\subsection{Impact of Sulfate Salts on Vehicles and Consumers}

Terminal and retail station issues were a significant nuisance, but the issue reached a crisis (in the words of one stakeholder) when vehicles were impacted and consumer protection could not be guaranteed. Although the automakers did not release specific numbers of vehicles affected, the number of incidents was significant enough to draw attention from the news media.

In 2003, two car makers found fuel injector cleaning and replacements spiked in frequency in Phoenix in the winter, when ethanol was added to the gasoline. Sulfate salts were found in the injectors, and the issue was also attributed to sulfate ion contamination in the ethanol.

In the fall of 2004, car dealers reported consumer complaints about poor driveability and difficulty starting cars, especially in colder weather in Milwaukee (Rutledge 2004a, Rutledge 2004b). The problems included rough idle, slow startup, misfire, and stuck fuel injectors and 
occurred for fuel purchased from two specific fuel marketers, and not all engine models were affected (General Motors Corporation [GM] vehicles and gasoline purchased from CITGO were mentioned in media reports [Rutledge 2004c]). An investigation by a General Motors determined that sodium sulfate was the cause of the injector sticking (Rutledge 2005a, Rutledge 2005b). In an interview, the car maker noted that their hypothesis at the time was that the problem came from the buildup of sulfate salt inside the injectors in warmer months, which led to sticking in colder months. However, efforts to recreate the problem in a vehicle control fleet were not successful. A fuel marketer in the Milwaukee area also conducted an extensive investigation and determined sulfate in ethanol was the root cause of the problem, with higher levels of sulfate in the ethanol leading to an increase in vehicle operational issues. This same marketer reported that changing to a different fuel additive eliminated the problem. The company set an internal specification at 1-ppm sulfate in the fuel ethanol in response to the consumer complaints and vehicle problems and reported no subsequent problems. Other than the hypothesis of ammonium cation coming from the fuel additive, no information was provided on the source of the cations involved in sulfate salt formation in any of our interviews or in documents that we reviewed.

\subsection{Summary}

The reported problems at terminals, retail stations, and in on-road vehicles are summarized in Table 3.

Table 3. Summary of Market Sulfate Salt Issues in 2003-05

\begin{tabular}{|c|c|c|}
\hline Date & Issue & Notes \\
\hline 2003-2004 & $\begin{array}{l}\text { Filter clogging and turbine meter problems } \\
\text { reported at terminals in Minnesota, Chicago, } \\
\text { and Milwaukee. }\end{array}$ & $\begin{array}{l}\text { Inconclusive filter analysis; turbine } \\
\text { meter deposits consisted of sodium } \\
\text { and ammonium sulfates }\end{array}$ \\
\hline March 2003 & $\begin{array}{l}\text { Filter plugging reported in St. Louis (implied at } \\
\text { retail). }\end{array}$ & Sodium sulfate found on filters \\
\hline July 2003 & $\begin{array}{l}\text { Filter plugging reported in Los Angeles (implied } \\
\text { at retail). }\end{array}$ & Sodium sulfate found on filters \\
\hline Summer 2003 & $\begin{array}{l}\text { Additive company laboratory studies concluded } \\
\text { that filter plugging stopped when a change was } \\
\text { made from competitor's additive or when an } \\
\text { additive was reformulated. }\end{array}$ & $\begin{array}{l}\text { Potential that additive interaction } \\
\text { exacerbates the issue }\end{array}$ \\
\hline $\begin{array}{l}\text { August- } \\
\text { September } \\
2003\end{array}$ & $\begin{array}{l}\text { A large shipment of ethanol was rejected in } \\
\text { California because of sodium sulfate } \\
\text { contamination. }\end{array}$ & - \\
\hline October 2003 & $\begin{array}{l}\text { Car makers report fuel injector repair/replace } \\
\text { rates increase in Phoenix coinciding with the } \\
\text { switch from summer gasoline to gasoline } \\
\text { containing ethanol. }\end{array}$ & - \\
\hline $\begin{array}{l}\text { November } \\
2003\end{array}$ & Roseville, MN filter plugging (retail implied). & Sodium sulfate found on filters \\
\hline May 2004 & $\begin{array}{l}\text { Fuel marketer investigation in Milwaukee } \\
\text { suggests a fuel additive or contaminant in a fuel } \\
\text { additive was interacting with sulfate ions to form } \\
\text { insoluble precipitate. }\end{array}$ & - \\
\hline
\end{tabular}




\begin{tabular}{|c|c|c|}
\hline Date & Issue & Notes \\
\hline May 2004 & $\begin{array}{l}\text { Ethanol supplier change in Los Angeles and } \\
\text { additive reformulation in other (unspecified) } \\
\text { markets appear to eliminate the problem with } \\
\text { (retail) filter plugging. }\end{array}$ & - \\
\hline June 2004 & $\begin{array}{l}\text { Sulfate salt issues were brought up at ASTM } \\
\text { Petroleum Products Committee meeting by fuel } \\
\text { marketers, but no action is taken. }\end{array}$ & $\begin{array}{l}\text { Some stakeholders stated that at } \\
\text { the time, the issue was believed to } \\
\text { be fuel-additive related }\end{array}$ \\
\hline Fall 2004 & $\begin{array}{l}\text { Motorists report driveability problems in } \\
\text { Milwaukee, including rough idle, misfire, and } \\
\text { failure to operate. Problem is reported to be } \\
\text { stuck fuel injectors. Replacing injectors solved } \\
\text { the problem temporarily, though some motorists } \\
\text { report recurrence as quickly as } 2 \text { days later. }\end{array}$ & $\begin{array}{l}\text { Problem was widely publicized by } \\
\text { the Milwaukee Journal Sentinel } \\
\text { newspaper. A newspaper report } \\
\text { linked the problems to gas from } \\
\text { CITGO and to predominantly GM } \\
\text { cars (Rutledge 2004b). }\end{array}$ \\
\hline October 2004 & $\begin{array}{l}\text { Filter plugging in the Pacific Northwest (retail } \\
\text { implied). }\end{array}$ & Sodium sulfate on filters \\
\hline February 2005 & $\begin{array}{l}\text { Fuel injector failures are again reported in } \\
\text { Milwaukee. A fuel marketer switches suppliers } \\
\text { and implements a 1-ppm sulfate specification for } \\
\text { denatured fuel ethanol, apparently resolving the } \\
\text { issue in Milwaukee for its customers. Other } \\
\text { retailers did not report widespread issues. A car } \\
\text { company study shows that injector sticking is } \\
\text { caused by sodium sulfate. }\end{array}$ & - \\
\hline February 2005 & $\begin{array}{l}\text { A fuel marketer reports market survey of fuel } \\
\text { ethanol showing an average of } 2.6 \mathrm{ppm} \text { sulfates } \\
\text { in } 314 \text { samples. }\end{array}$ & - \\
\hline $\begin{array}{l}\text { March-April } \\
2005\end{array}$ & $\begin{array}{l}\text { Milwaukee media outlet reports that GM and } \\
\text { CITGO believe the problem is caused by excess } \\
\text { sulfate in fuel ethanol, but that the issues have } \\
\text { largely been eliminated in the market by this } \\
\text { time (Rutledge 2005b). }\end{array}$ & - \\
\hline June 2005 & $\begin{array}{l}\text { At the ASTM meeting, fuel marketers and car } \\
\text { companies propose to ballot at 1-ppm sulfate } \\
\text { limit, the motion passed. }\end{array}$ & - \\
\hline $\begin{array}{l}\text { September } \\
2005\end{array}$ & $\begin{array}{l}\text { Representatives from refining, auto, and ethanol } \\
\text { industries meet to discuss the ethanol sulfate } \\
\text { limit. It was agreed to issue a second ballot for a } \\
\text { 4-ppm sulfate limit. }\end{array}$ & $\begin{array}{l}\text { Participants recognized that } 4 \mathrm{ppm} \\
\text { might not be protective, and agreed } \\
\text { that if issues continued, a lower limit } \\
\text { would be implemented in a } \\
\text { subsequent ballot. }\end{array}$ \\
\hline $\begin{array}{l}\text { December } \\
2005\end{array}$ & $\begin{array}{l}\text { The 4-ppm limit for sulfate in D4806 passes at } \\
\text { ASTM after negatives were declared non- } \\
\text { persuasive. }\end{array}$ & - \\
\hline
\end{tabular}




\section{ASTM Activities}

\subsection{Adding a Sulfate Limit to D4806}

Prior to the mid-2000s, sulfate content in fuel ethanol was not limited in the applicable ASTM specification, D4806 "Standard Specification for Denatured Fuel Ethanol for Blending with Gasolines for Use as Automotive Spark-Ignition Engine Fuel.” In 2005, a petroleum products marketer reported sulfate concentrations in fuel ethanol from $0.1 \mathrm{ppm}$ to $23 \mathrm{ppm}$, with an average of $2.6 \mathrm{ppm}$, and a market survey presented by the ethanol industry showed sulfate contents varying from less than $0.4 \mathrm{ppm}$ up to $10 \mathrm{ppm}$. Oil and auto industry representatives proposed a 1-ppm limit on sulfate be added to D4806 at the June 2005 ASTM meeting.

The proposal for a 1-ppm limit on sulfate in fuel ethanol was met with resistance by the ethanol industry for the following reasons:

- Sulfate in ethanol was never definitively linked to injector plugging, and while the observation that implementing a 1-ppm sulfate limit eliminated the problem is important, cause and effect were never established, and other factors may also have contributed.

- Should a specification on sulfates be put into the ethanol specification or the gasoline (finished fuel) specification?

- What was the scientific basis for proposing a 1-ppm sulfate limit?

- What is the role of additives?

- Ethanol is comingled at the terminal, and product quality has consistently improved, so what has changed recently that could cause this issue?

- What test method should be used to test for sulfate in ethanol?

These questions are still relevant today; the source of the sodium or ammonium cations needed to form the sodium sulfate precipitate is another key unanswered question.

Ultimately, it was recognized by the members of the ASTM Gasoline and Oxygenated Fuels Subcommittee that there was no consensus for the 1-ppm sulfate limit. All stakeholders interviewed confirmed that a 4-ppm limit on sulfate was included in D4806 as a compromise. This compromise was necessary because of the lack of data definitively linking sulfate ions in ethanol to the sodium sulfate deposits observed in turbine meters, filters, and fuel injectors, and because there was a lack of data showing a specific threshold sulfate level below which problems would not occur. For example, a 5-ppm sulfate limit might also have been protective of consumers, but there was no scientific information on which to base selection of a limit. The stakeholders agreed to this negotiated limit with the understanding that if problems continued and the data showed a revised limit was more appropriate, a change would be made in a future revision of D4806.

\subsection{Specification Limits}

Table 4 shows the sulfate limits on denatured fuel ethanol in the United States, European Union, and Brazil, including applicable test methods. All three standards have limits on sulfate in the ethanol, not the finished gasoline containing ethanol. There are no specification limits on the cations in the finished fuel. 
Table 4. Sulfate Specification Limits in Denatured Fuel Ethanol

\begin{tabular}{llll}
\hline Region & Applicable Standard & $\begin{array}{l}\text { Allowable } \\
\text { Concentration }\end{array}$ & $\begin{array}{l}\text { Measurement } \\
\text { Method }\end{array}$ \\
\hline $\begin{array}{l}\text { United } \\
\text { States }\end{array}$ & $\begin{array}{l}\text { ASTM 4806-16a Standard Specification for } \\
\text { Denatured Fuel Ethanol for Blending with } \\
\text { Gasolines for Use as Automotive Spark-Ignition } \\
\text { Engine Fuel }\end{array}$ & $4 \mathrm{ppm}$ & $\begin{array}{l}\text { ASTM D7318, 7319 } \\
\text { or 7328 }\end{array}$ \\
$\begin{array}{l}\text { European } \\
\text { Union }\end{array}$ & $\begin{array}{l}\text { Automotive Fuels - Ethanol (E85) - Automotive } \\
\text { fuel - Requirements and test methods technical } \\
\text { specification, CEN/TS 15293:2011 }\end{array}$ & $4 \mathrm{ppm}$ & EN 15492 \\
Brazil & $\begin{array}{l}\text { Brazilian ANP Fuel Ethanol Specification } \\
\text { Resolution ANP \#19 April 15, 2015 for hydrous } \\
\text { ethanol }\end{array}$ & $4 \mathrm{ppm}$ & NBR Method 10894 \\
\hline
\end{tabular}

\subsection{ASTM Test Methods}

The original ASTM test method adopted for sulfate determination, D7318, measured only existent sulfate, or sulfate that is already present in the ethanol. Because sulfite can oxidize to sulfate over time (Wilkinson 1993, Rowe 2006), methods were developed to measure both existent and potential sulfate concentrations. Potential sulfate, or sulfite, could be measured by forcing oxidation to sulfate in these test methods. However, no data has been presented to correlate the oxidation expected in the distribution system with the chemical oxidation in an analytical method.

\subsubsection{D7318 Standard Test Method for Existent Inorganic Sulfate in Ethanol by Potentiometric Titration}

This method uses lead nitrate to titrate the sulfate in ethanol. The lead complexes with the sulfate ions, forming lead sulfate. When the sulfate ions have been titrated, the lead ion concentration begins to increase. A lead-selective electrode is used measure the end point. This method is not often used due to the toxicity of the lead titration solution, and many laboratories prohibit test methods using lead.

The method has an applicable range of existent sulfate of 1.0-20 ppm. The method does not measure potential sulfate. Table 5 lists the repeatability $(r)$ and reproducibility $(R)$ of the method over a range of sulfate contents. Repeatability is the difference in repeated analyses on the same sample, by the same operator, in the same laboratory, in essence intra-laboratory precision. Reproducibility is the difference in repeated analyses on the same sample by two different operators in different laboratories, or the inter-laboratory precision. 
Table 5. D7318-13 $r$ and R for Existent Sulfate

\begin{tabular}{lllll}
\hline Sulfate, ppm & Existent $\mathbf{r}$ & $\begin{array}{l}\mathbf{r} \text { as percent } \\
\text { of sulfate }\end{array}$ & Existent $\mathbf{R}$ & $\begin{array}{l}\mathbf{R} \text { as percent } \\
\text { of sulfate }\end{array}$ \\
\hline 1 & 0.18 & $18 \%$ & 0.60 & $60 \%$ \\
4 & 0.25 & $6.3 \%$ & 0.85 & $21 \%$ \\
10 & 0.32 & $3.2 \%$ & 1.08 & $11 \%$ \\
20 & 0.38 & $1.9 \%$ & 1.30 & $6.5 \%$ \\
\hline
\end{tabular}

\subsubsection{D7319 Standard Test Method for Determination of Existent and Potential Sulfate and Inorganic Chloride in Fuel Ethanol and Butanol by Direct Injection Suppressed Ion Chromatography}

The D7319 method measures both existent and potential sulfate, along with chloride in fuel ethanol. The existent sulfate method uses a direct injection of the ethanol sample into an ion chromatograph with the appropriate columns and detector. This method is commonly used due to its simplicity. To measure potential sulfate, the sample is oxidized with hydrogen peroxide and injected into the ion chromatograph.

Method D7319 measures existent and potential sulfate in the range of $1.0-20 \mathrm{ppm}$. The $\mathrm{r}$ and $\mathrm{R}$ of the method are shown in Table 6.

Table 6. D7319-13 $r$ and R for Existent and Potential Sulfate

\begin{tabular}{lllllllll}
\hline $\begin{array}{l}\text { Sulfate, } \\
\text { ppm }\end{array}$ & $\begin{array}{l}\text { Existent } \\
\mathbf{r}\end{array}$ & $\begin{array}{l}\mathbf{r} \text { as } \\
\text { percent } \\
\text { of sulfate }\end{array}$ & $\begin{array}{l}\text { Existent } \\
\mathbf{R}\end{array}$ & $\begin{array}{l}\mathbf{R} \text { as } \\
\text { percent } \\
\text { of sulfate }\end{array}$ & $\begin{array}{l}\text { Potential } \\
\mathbf{r}\end{array}$ & $\begin{array}{l}\mathbf{r} \text { as } \\
\text { percent } \\
\text { of sulfate }\end{array}$ & $\begin{array}{l}\text { Potential } \\
\mathbf{R}\end{array}$ & $\begin{array}{l}\mathbf{R} \text { as } \\
\text { percent } \\
\text { of sulfate }\end{array}$ \\
\hline 1 & 0.09 & $9 \%$ & 1.23 & $123 \%$ & 0.14 & $14 \%$ & 1.41 & $141 \%$ \\
4 & 0.21 & $5.3 \%$ & 2.92 & $73 \%$ & 0.36 & $9 \%$ & 3.51 & $88 \%$ \\
10 & 0.38 & $3.8 \%$ & 5.16 & $52 \%$ & 0.74 & $7.4 \%$ & 7.23 & $72 \%$ \\
20 & 0.58 & $2.9 \%$ & 7.95 & $40 \%$ & 1.32 & $6.6 \%$ & 12.85 & $64 \%$ \\
\hline
\end{tabular}

\subsubsection{D7328 Standard Test Method for Determination of Existent and Potential Inorganic Sulfate and Total Inorganic Chloride in Fuel Ethanol by lon Chromatography Using Aqueous Sample Injection}

In this method sulfate concentration is measured by evaporating the ethanol and analyzing the residue. The method is also able to measure inorganic chloride. This method is also frequently used by industry. For existent sulfate, the sample is reconstituted in water prior to injection into an ion chromatograph. To measure potential sulfate, the sample is reconstituted in a hydrogen peroxide solution prior to analysis. The method is applicable for existent sulfate between 0.55 and $20 \mathrm{ppm}$ and potential sulfate between 4.0 and $20 \mathrm{ppm}$. The method precision is presented in Table 7. This method has the lowest detection limit for existent sulfate of the three available methods, but the detection limit for potential sulfate is four times higher than the D7319 method. 
Table 7. D7328-13 r and R for Existent and Potential Sulfate

\begin{tabular}{lllllllll}
\hline $\begin{array}{l}\text { Sulfate, } \\
\text { ppm }\end{array}$ & $\begin{array}{l}\text { Existent } \\
\mathbf{r}\end{array}$ & $\begin{array}{l}\mathbf{r} \text { as } \\
\text { percent } \\
\text { of sulfate }\end{array}$ & $\begin{array}{l}\text { Existent } \\
\mathbf{R}\end{array}$ & $\begin{array}{l}\mathbf{R} \text { as } \\
\text { percent } \\
\text { of sulfate }\end{array}$ & $\begin{array}{l}\text { Potential } \\
\mathbf{r}\end{array}$ & $\begin{array}{l}\mathbf{r} \text { as } \\
\text { percent } \\
\text { of sulfate }\end{array}$ & $\begin{array}{l}\text { Potential } \\
\mathbf{R}\end{array}$ & $\begin{array}{l}\mathbf{R} \text { as } \\
\text { percent } \\
\text { of sulfate }\end{array}$ \\
\hline 1 & 0.23 & $23 \%$ & 1.10 & $110 \%$ & - & - & - & - \\
4 & 0.46 & $12 \%$ & 2.19 & $55 \%$ & 0.31 & $7.8 \%$ & 1.83 & $46 \%$ \\
10 & 0.73 & $7.3 \%$ & 3.47 & $35 \%$ & 0.44 & $4.4 \%$ & 2.64 & $26 \%$ \\
20 & 1.04 & $5.2 \%$ & 4.90 & $25 \%$ & 0.58 & $2.9 \%$ & 3.48 & $17 \%$ \\
\hline
\end{tabular}

\subsubsection{Method Limitations}

The most significant limitation of the methods discussed is that they can only be used in fuel ethanol and not gasoline with or without ethanol. However, the D7319 method can be modified to include hydrocarbon-only gasoline and gasoline containing ethanol. Examples of the methodology are available in the literature (Metrohm 2017), though the modification has not been standardized at ASTM yet.

None of the methods have tight precision. At the specification limit of 4-ppm existent sulfate, the inter-laboratory precision ranges from $0.85 \mathrm{ppm}(21 \%$ of the specification limit for D7318) to $2.92 \mathrm{ppm}(\sim 55 \%$ of the specification limit for D7328). Any discussion of the appropriate sulfate limit in fuel ethanol needs to include development of improvements to the precision of the test methods. 


\section{Conclusions}

Sulfate salt deposits were found on clogged terminal filters and turbine meters, clogged retail fuel filters, and malfunctioning consumer vehicle fuel injectors used for E10 in 2004 and 2005. While there is evidence supporting the idea that sulfate anions in the ethanol contributed to the presence of these sulfate deposits, it is not clear if this was the only factor. Sulfate ions may enter fuel ethanol from several different sources. There is some evidence (or at least a hypothesis) that sulfite anions in ethanol, which are soluble in the presence of sodium cations, can oxidize to form sulfate that forms an insoluble sodium salt. Sulfite may be added to the fermentation process in some process configurations, can be produced by some yeast strains, or may come from other sources that we were unable to identify. The counter cation in fuel ethanol is most likely hydrogen ions, $\mathrm{H}^{+}$. Hydrogen ions form when $\mathrm{SO}_{2}$ is dissolved in water (formally as sulfurous acid, $\mathrm{H}_{2} \mathrm{SO}_{3}$ ). Sodium and other inorganic cations would be removed in the ethanol distillation. Because of the high solubility of sulfuric acid $\left(\mathrm{H}_{2} \mathrm{SO}_{4}\right)$ in ethanol, no salt precipitation could occur unless another cation such as sodium or ammonium was added, leading to precipitation of these much less soluble sulfates. There are possible sources of sodium and sulfate ions from petroleum refining; however, no data has been presented to implicate the hydrocarbons as a source of sodium or sulfates during the 2004-2005 period when sulfate salts were an issue.

For the terminal, retail, and vehicle operability issues occurring in 2004 and 2005, no source of a cation such as sodium or ammonium that would cause the sulfate salts to precipitate was identified. There is some evidence supporting that the problem was a fuel additive compatibility issue, and a fuel additive may have been the source of the precipitating cation. The hydrocarbon blendstock used to make the E10 may also have been the source of the sodium cation either through contamination at the petroleum refinery (salt dryer or caustic wash) or via contact with tank water bottoms. In markets using E10 seasonally or for the first time, the ethanol or E10 may also have come into contact with water bottoms containing sodium and other cations.

A 4-ppm limit for sulfate ion was added to the D4806 standard for denatured fuel ethanol, but without a clear scientific basis. The 4-ppm limit was a negotiated compromise based on engineering judgement; it was not possible to determine whether or not a 5- or 6-ppm limit would have been equally adequate to resolve the issue.

A much better understanding of the solubility of sulfates containing various cations in ethanol, hydrocarbons, and ethanol-hydrocarbon blends is needed to avoid future issues with sulfate salts as ethanol levels in gasoline are increased. This understanding can only be developed with improvements to current analytical methods. A better understanding of the importance of and factors affecting the oxidation of sulfite to sulfate is desirable, including the availability of oxygen in the fuel distribution system. Clarity on the source of inorganic cations and anions in gasoline is also needed. Specific recommendations are discussed in the next section. 


\section{Recommendations}

The path forward to avoiding future issues with sulfate salts as ethanol levels in gasoline are increased is to develop a better fundamental understanding of sulfite and sulfate ion chemistry, including the chemistry of the charge balancing cations in these fluids. Research analytical methods for sulfite and sulfate, and sodium and other cations in ethanol, hydrocarbons, and hydrocarbon-ethanol blends that have lower detection limits and greater precision should be developed. These improved methods will allow the necessary measurements of sulfite and sulfate salt solubility over a range of temperatures in denatured ethanol, hydrocarbon blendstock, and finished gasolines containing ethanol. A more detailed understanding of the fate of sulfite, sulfate, and sodium in ethanol beer distillation should be developed. The factors affecting the rate of sulfite oxidation to sulfate in denatured fuel ethanol should be studied. The levels of sodium and other inorganic ions in hydrocarbon blendstocks - leaving the refinery and at the terminal prior to ethanol blending - should be measured.

\subsection{Improved Analytical Methodology}

To understand the complex issues with sulfate salts in the ethanol-gasoline system, improved limits of detection and precision are needed for methods used to measure sulfate anion in denatured fuel ethanol, as well as for measurement of sulfite and cations such as sodium and ammonium. New methods with very low detection limits and high precision are needed for measurement of these ions in finished gasoline as well. This improved methodology is necessary to carry out all of the other research recommendations discussed below.

The preferred approach is to improve the precision and lower the detection limits of the D7319 and D7328 methods currently used by industry for sulfate content of ethanol. If these methods could be modified to work for hydrocarbon gasoline and ethanol blends, that would also be ideal. Expansion of these methods for measurement of the full range of relevant cations (sodium, ammonium, and perhaps others) is also necessary. A first step will be discussions with instrument manufacturers on ways to achieve lower detection and improved precision. A literature review encompassing similar methods should also be conducted.

Based on preliminary discussions with instrument manufacturers, it appears that a matrix elimination/ion chromatography technique may be the best path forward to quantifying ions in hydrocarbon blendstocks and ethanol blends. This can be done with a modification to existing equipment for D7319 (Metrohm 2017, ThermoFischer 2017). The matrix elimination technique has been well studied and is suitable to complex gasoline-ethanol matrices.

\subsection{Basic Chemistry}

\subsubsection{Solubility of Sulfite and Sulfate Salts}

Very little quantitative information was available on the solubility of sulfate and sulfite salts in pure ethanol, denatured fuel ethanol, hydrous ethanol (E95), gasoline containing ethanol, or hydrocarbon-only gasoline at low levels. Very low solubility is typically assumed, but this means less than $1 \mathrm{~g} / 100 \mathrm{~mL}$ or about $1 \mathrm{wt} \%(10,000 \mathrm{ppm})$. Understanding solubility at much lower levels is of great interest as basic data for understanding issues with sulfate salts in vehicles and the setting of a sulfate limit for fuel ethanol and finished fuels. Solubility of other relevant salts is also important. We recommend a study to measure solubility at levels as low as $0.1 \mathrm{ppm}$ for the 
relevant salts, including the effects of market-relevant levels of water, temperature, and blends ranging from pure ethanol to hydrocarbon-only gasoline. As noted, the activity to develop improved analytical methods is critical for accomplishing the solubility effort.

\subsubsection{Oxidation of Sulfite to Sulfate}

As discussed in this report, there is some evidence (or at least a hypothesis) that sulfite anion in ethanol, which may be soluble in the presence of sodium or ammonium cations, can oxidize to form sulfate that forms insoluble salts. Of interest is the mechanism and rate of sulfite oxidation, how it is affected by $\mathrm{pH}$ and the presence of trace metals, how much oxygen is available in the distribution system, and a better understanding of which ions must be present to form insoluble salts. The effect of blending with hydrocarbon gasoline on sulfite oxidation and sulfate salt precipitation should also be investigated.

\subsection{Inorganic Ions in Hydrocarbon Blendstocks and Additives}

The levels of inorganic cations (sodium and ammonium in particular) and anions (sulfite, sulfate, and chloride, for example) in the hydrocarbon blendstocks used for preparing ethanol-gasoline blends have not been quantified during normal operation or after a refinery upset. While it may prove difficult to obtain blendstocks for oxygenate blending from terminals and refineries, an effort should be made to do so, and these should be analyzed for the ions of interest. In addition, detergent, corrosion inhibitor, and other additives may also include inorganic ions. An effort to work with the additive suppliers to understand what these are and the extent to which they might contribute, or might have contributed in the past, to salt precipitation issues should be undertaken. 


\section{References}

Albright, L.F. 2003. "Alkylation of Isobutane with C3-C5 Olefins To Produce High-Quality Gasolines: Physicochemical Sequence of Events” Ind. Eng. Chem. Res. 42:4283-4289.

Albright, L.F. 2009. "Present and Future Alkylation Processes in Refineries" Ind. Eng. Chem. Res. 48:1409-1413.

Alliance of Automobile Manufacturers, 2011. North American Fuel Survey.

am Ende, D.J., and L.F. Albright. 1994. "Degradation and Isomerization of Isoparaffins while in Contact with Sulfuric Acid in Alkylation Units: Chemistry and Reaction Kinetics." Ind. Eng. Chem. Res. 33:840-848.

Ashida, T., Y. Takei, and H. Hosi. 2001. "Effects of Fuel Properties on SID Fuel Injector Deposit." SAE 2001-01-3694.

ASTM D4806-16a. 2016. "Standard Specification for Denatured Fuel Ethanol for Blending with Automotive Spark-Ignition Engine Fuel.” ASTM International. West Conshohocken, PA. www.astm.org.

ASTM D5500-16. 2016. "Standard Test Method for Vehicle Evaluation of Unleaded Automotive Spark-Ignition Engine Fuel for Intake Valve Deposit Formation.” ASTM International. West Conshohocken, PA. www.astm.org.

ASTM D5598-01. 2012. "Standard Test Method for Evaluating Unleaded Automotive SparkIgnition Fuel for Electronic Port Fuel Injector Fouling.” ASTM International. West

Conshohocken, PA. www.astm.org.

ASTM D6201-04. 2014. Standard Test Method for Dynamometer Evaluation of Unleaded Spark-Ignition Engine Fuel for Intake Valve Deposit Formation.” ASTM International. West Conshohocken, PA. www.astm.org.

ASTM D6421-99a. 2014. "Standard Test Method for Evaluating Automotive Spark-Ignition Engine Fuel for Electronic Port Fuel Injector Fouling by Bench Procedure.” ASTM International. West Conshohocken, PA. www.astm.org.

ASTM D7318-13. 2013. "Standard Test Method for Existent Inorganic Sulfate in Ethanol by Potentiometric Titration.” ASTM International. West Conshohocken, PA. www.astm.org.

ASTM D7319-13. 2013. "Standard Test Method for Determination of Existent and Potential Sulfate and Inorganic Chloride in Fuel Ethanol and Butanol by Direct Injection Suppressed Ion Chromatography.” ASTM International. West Conshohocken, PA. www.astm.org.

ASTM D7328-16. 2016. "Standard Test Method for Determination of Existent and Potential Inorganic Sulfate and Total Inorganic Chloride in Fuel Ethanol by Ion Chromatography Using Aqueous Sample Injection.” ASTM International. West Conshohocken, PA. www.astm.org. 
Barker, J., S. Cook, and P. Richards. 2013. "Sodium Contamination of Diesel Fuel, its Interaction with Fuel Additives and the Resultant Effects on Filter Plugging and Injector Fouling," SAE Int. J. Fuels Lubr. 6(3):826-838, doi: 10.4271/2013-01-2687.

Barnett, J.W. 1996. "New Salt Product Dries Distillate Streams, Eliminates Haze.” Oil \& Gas Journal April 15, 1996.

Bechtold, Richard L. 1987. Compendium of Significant Events in the Recent Development of Alcohol Fuels in the United States. Oak Ridge, TN: Oak Ridge National Laboratory. Report No. ORNL/Sub/85-22007/1.

Bitting, B., F. Gschwendtner, W. Kohlhepp, M. Kothe, C.J. Testroet, and K.H. Ziwica. 1987. "Intake Valve Deposits - Fuel Detergency Requirements Revisited." SAE Technical Paper 872117. doi:10.4271/872117. http://papers.sae.org/872117/

Carlisle, H.W., R.W. Frew, J.R. Mills, A.A. Aradi, and N.L. Avery. 2001. “The Effect of Fuel Composition and Additive Content on Injector Deposits and Performance of an Air-Assisted Direct Injection Spark Ignition (DISI) research Engine.” SAE Technical Paper 2001-01-2030. http://papers.sae.org/2001-01-2030/

Chapman, E., J. Cummings, and D. Conran. 2013. "Effects of Gasoline and Ethanol Fuel Corrosion Inhibitors on Powertrain Intake Valve Deposits." SAE Int. J. Fuels Lubr. 6(1):63-79, doi:10.4271/2013-01-0893. http://papers.sae.org/2013-01-0893/

Crude Oil Windfall Profits Tax of 1980, Pub. L. No. 96-223, 1980.

Dean, J., ed. Lange's Handbook of Chemistry, 13th ed., 1985. doi.org/10.1080/10426919008953291.

Dearn, K., J. Xu, H. Ding, H. Xu, A. Weall, P. Kirby, B. Cooper, I. Edington, and J. KruegerVenus. 2014. "An Investigation in the Characteristics of DISI Injector Deposits Using Advanced Analytical Methods." SAE Int. J. Fuels Lubr. 7(3):771-782, 2014, doi:10.4271/2014-01-2722. http://papers.sae.org/2014-01-2722/

DuMont, R.J., L. Cunningham, M.K. Oliver, W.M. Studzinski, and J.M. Galante-Fox. 2007. "Controlling Induction System Deposits in Flexible Fuel Vehicles Operating on E85." SAE Technical Paper 2007-01-4071. http://papers.sae.org/2007-01-4071/

Edwards, T.J., J. Newman, and J.M. Prausnitz. 1975. "Thermodynamics of Aqueous Solutions Containing Volatile Weak Electrolytes.” AIChE Journal 21(2):248-259. http://onlinelibrary.wiley.com/doi/10.1002/aic.690210205/abstract

Fernandes, H., S.L. Braga, L.C. Braga, C.V.M. Braga, and A.R.F. de Aguiar Martins. 2012. "Fuel Sulfate Content Influence in the Formation of Inorganics Components Deposits in the Engine Injectors with Technologies of Gasoline Direct Injection.” SAE Technical Paper 201236-0314. doi:10.4271/2012-36-0314.http://papers.sae.org/2012-36-0314/ 
Gething, J.A. 1987. "Performance-Robbing Aspects of Intake Valve and Port Deposits." SAE Technical Paper 872116. doi:10.4271/872116. http://papers.sae.org/872116/

Goldberg, R.N., and V.B. Parker. 1985. "Thermodynamics of Solution of $\mathrm{SO}_{2}(\mathrm{~g})$ in Water and of Aqueous Sulfur Dioxide Solutions." J Res. Nat. Bur. Stand. 90(5):341-358. http://nvlpubs.nist.gov/nistpubs//res/090/jresv90n5p341 A1b.pdf

Guido, L.F. 2016. "Sulfites in Beer: Reviewing Regulation, Analysis, and Role.” Sci. Agric. 73(2):189-197.

Houser, K.R., and T.A. Crosby. 1992. "The Impact of Intake Valve Deposits on Exhaust Emissions.” SAE Technical Paper No. 922259. http://papers.sae.org/922259/

Ilett, D.R. 1995. "Aspects of the Analysis, Role, and Fate of Sulphur Dioxide in Beer - A Review." MBAA Quarterly 32:213-221.

http://community.mbaa.com/HigherLogic/System/DownloadDocumentFile.ashx?DocumentFile $\underline{K e y=79839 f 18-348 f-4610-a a f 9-d b e 941 b c 81 d 2 \& \text { forceDialog }=0}$

Keuken, H., 2014. "Corrosion Issues of Ethanol Blends and the Effect of Water." Presentation, ABLCNext Conference, November 11, 2014. http://www.process-designcenter.com/shared/hydrousethanol/Presentations/2014\%20PDC\%20ABLCNext $\% 20 \% 20$ Presentation $\% 20$ \%20Corrosion $\% 20$ issues $\% 20$ of $\% 20$ ethanol $\% 20$ blends $\% 20$ and $\% 20$ the $\% 20$ effect $\% 20$ of $\% 20$ wate r.pdf

Kranz, K. 2008. "Intro to Alkylation Chemistry - Mechanisms, Operating Variables, and Olefin Interactions.” DuPont ${ }^{\mathrm{TM}}$ STRATCO ${ }^{\circledR}$ Clean Fuel Technology, September 2008. http://www.dupont.com/content/dam/dupont/products-and-services/consulting-services-andprocess-technologies/consulting-services-and-process-technologieslanding/documents/AlkylationChemistry_RU.pdf

Luecke, J., and R.L. McCormick. 2014. "Electrical Conductivity and pHe Response of Ethanol Contaminants." Energy Fuels 28(8):5222-5228. http://pubs.acs.org/doi/abs/10.1021/ef5013038

Mamrosh, D., C. Beitler, K. Fisher, and S. Stem. 2008. "Consider Improved Scrubbing Designs for Acid Gases." Hydrocarbon Proc. January 2008. http://www.trimeric.com/assets/considerimproved-scrubbing-designs-for-acid-gases.pdf

Metrohm. 2017. "Anions in a Gasoline/Bioethanol Mixture using Inline Matrix Elimination." IC Application Note No. AN-S-244. https://www.metrohm.com/en/applications/\%7BFB9D0AC656ED-480E-9CBB-3C26E7F4588D\%7D. Accessed January 27, 2017.

Nalco. 2009. "Fuel Ethanol Sulfate Contamination." Presented to 2009 Reliability \& Maintenance Conference.

Ojeda Toro, J.C., I. Dobrosz-Gómez, and M.A. Gómez García. 2014. “Sodium Sulfate Solubility in (Water + Ethanol) Mixed Solvents in the Presence of Hydrochloric Acid: Experimental Measurements and Modeling." Fluid Phase Equilibria 384:106-113. 
Renewable Fuels Association. 2016. "Fueling a High Octane Future." 2016 Annual Ethanol Outlook. http://www.ethanolrfa.org/wp-content/uploads/2016/02/Ethanol-Industry-Outlook2016.pdf. Accessed January 27, 2017.

Retka Shill, S. 2016. "Sulfur Compounded in Ethanol Regulations." Ethanol Producer Magazine. http://ethanolproducer.com/articles/13513/sulfur-compounded-in-ethanol-regulations, accessed October 14, 2016.

Rowe, D.W. 2006. "Meeting the Analytical Requirements for Sulfate in Ethanol." Ethanol Producer Magazine October 2, 2006. http://www.ethanolproducer.com/articles/2381/meetingthe-analytical-requirements-for-sulfate-in-ethanol

Russell, M., J. Cummings, T. Cushing, and W. Studzinski. 2013. "Cellulosic Ethanol Fuel Quality Evaluation and its Effects on PFI Intake Valve Deposits and GDI Fuel Injector Plugging Performance.” SAE Technical Paper 2013-01-0885. http://papers.sae.org/2013-01-0885/

Rutledge, R. 2004a. "Rash of Costly Repairs has Some Experts Suspecting Tainted Gas." Milwaukee Journal Sentinel, October 19, 2004.

Rutledge, R. 2004b. "Memo Fuels Injector Debate: State Inspector Wrote that Ethanol May Have Played Role in Failures.” Milwaukee Journal Sentinel, December 4, 2004.

Rutledge, R. 2004c. “GM, CITGO Turn Up Often in Injector Issue.” Milwaukee Journal Sentinel, December 26, 2004.

Rutledge, R. 2005a. “Clogged Injectors Traced to Sulfates GM Says It Has Found Cause of Malfunctions in Thousands Of Area Cars" Milwaukee Journal Sentinel, January 8, 2005.

Rutledge, R. 2005b. "Ethanol Suspect in Fouled Injectors: GM Quietly Noting Sulfuric Acid Residue.” Milwaukee Journal Sentinel, March 25, 2005.

Sanchez, O.J., and C.A. Cardona. 2008. "Trends in Biotechnological Production of Fuel Ethanol from Different Feedstocks.” Bioresource Technology 99(13):5270-5295. http://www.sciencedirect.com/science/article/pii/S0960852407009376

Schwab, S., J.J. Bennett, S. Dell, S., J. Galante-Fox, A.M. Kulinowski, and K.T. Miller. 2010. "Internal Injector Deposits in High-Pressure Common Rail Diesel Engines." SAE Int. J. Fuels Lubr. 3(2):865-878. doi:10.4271/2010-01-2242. http://papers.sae.org/2010-01-2242/

Shandera, D.L., and D.S. Jackson. 1996. "Effect of Corn Wet-Milling Conditions (Sulfur Dioxide, Lactic Acid, and Steeping Temperature) on Starch Functionality." Cereal Chem. 73(5):632-637. http://www.aaccnet.org/publications/cc/backissues/1996/documents/73 632.pdf

Smith, S.S., and W. Imoehl. 2013. "Measurement and Control of Fuel Injector Deposits in Direct Injection Gasoline Vehicles.” SAE Technical Paper 2013-01-2616. http://papers.sae.org/2013$\underline{01-2616 /}$ 
Steel Tank Institute. 2006. "Keeping Water out of Your Storage System."

http://www.steeltank.com/Portals/0/pubs/recprac/KeepingWaterOutofYourStorageSystem_updat ed\%20_2_.pdf. Accessed May 9, 2017.

Sullivan, Dennis. 2004. "The Role of the Merox ${ }^{\mathrm{TM}}$ Process in the Era of Ultra Low Sulfur Transportation Fuels." Presentation to $5^{\text {th }}$ EMEA Catalyst Technology Conference, March 3-4, 2004. https://www.uop.com/?document=uop-the-role-of-the-merox-process-in-ultra-low-sulfurtransport-fuels-production-tech-paper\&download=1. Accessed February 2, 2017.

ThermoFischer, 2017. "Determination of Sulfate and Chloride in Ethanol by Ion Chromatography. Application Note 175."

http://tools.thermofisher.com/content/sfs/brochures/39541-AN175_LPN1827.pdf. Accessed May $30,2017$.

Tokunaga, J. 1974. "Solubilities of Sulfur Dioxide in Aqueous Alcohol Solutions." J. Chem. Eng. Data 19(2):162-165. http://pubs.acs.org/doi/abs/10.1021/je60061a009

"Top Tier ${ }^{\mathrm{TM}}$ Detergent Gasoline Deposit Control Performance Standard Revision D - May 2016." 2016. http://www.toptiergas.com/deposit-control/. Accessed February 4, 2017.

United States Environmental Protection Agency. 2016a. "Renewable Fuel Standard Program.” https://www.epa.gov/renewable-fuel-standard-program. Accessed May 8, 2017.

United States Environmental Protection Agency. 2016b. Investigation of Corrosion-Influencing Factors in Underground Storage Tanks with Diesel Service. EPA 510-R-16-001. https://www.epa.gov/ust/investigation-corrosion-influencing-factors-underground-storage-tanksdiesel-service. Accessed May 8, 2017.

Urrejola, S., A. Sanchez, and M.F. Hervello. 2011. "Solubilities of Sodium, Potassium, and Copper(II) Sulfates in Ethanol-Water Solutions.” J. Chem. Eng. Data 56(5):2687-2691. http://pubs.acs.org/doi/abs/10.1021/je100979d

Vener, R.E., and A.R. Thompson. 1950. "Solubility and Density Isotherms, Sodium SulfateEthyl Alcohol-Water." Ind. Eng. Chem. January. http://pubs.acs.org/doi/pdf/10.1021/ie50481a044

Vilardo, J.S., D. Arters, K. Corkwell, and C.L. Cerda de Groote. 2007. “A Comprehensive Examination of the Effect Ethanol-Blended Gasoline on Intake Valve Deposits in Spark-Ignited Engines." SAE Technical Paper No. 2007-01-3995. doi:10.4271/2007-01-3995. http://papers.sae.org/2007-01-3995/

Wilkinson, P.M., B. Doldersum, P.H.M.R. Cramers, and L.L. Van Dierendonck. 1993. "The Kinetics of Uncatalyzed Sodium Sulfite Oxidation." Chem. Eng. Sci. 48(5):933-941. http://www.sciencedirect.com/science/article/pii/000925099380331J 
Xu, H., C. Wang, X. Ma, Asish K. Sarangi, A. Weall, and J. Krueger-Venus. 2015. "Fuel Injector Deposits in Direct-Injection Spark-Ignition Engines." Progress in Energy and Combustion Science 50:63-80.

http://www.sciencedirect.com/science/article/pii/S0360128515000131

Zhang, Q., J. Du, Y. Jin, Z. Zhao, and Y. Li. 2013. " $\mathrm{SO}_{2}$ Reduction in Distilled Grape Spirits by Three Methods.” J. Inst. Brew. 119(4):314-320.

http://onlinelibrary.wiley.com/doi/10.1002/jib.100/pdf

Zupanovich, J.D. 2002. "Oxidation and Degradation Products of Common Oxygen Scavengers." The Analyst. https://www.awt.org/pub/0149322F-0C20-5CEC-AE62-1E826AF61A4C . Accessed May 17, 2017. 


\section{Appendix A: Fuel Injector and Intake Valve Deposits}

Fuel injectors are valves that meter the amount and timing of the fuel supplied to the engine. Fuel injectors have different designs that may affect the potential for deposit formation. Some early electronically controlled fuel injectors were inside the throttle body, well upstream of the intake valves; most cars newer than the mid-2000s have port fuel injectors and some fraction of late model cars have direct injectors. Port fuel injection times and meters the fuel into each chamber independently at the intake port from a pressurized fuel rail (or manifold, see Figure A-1). Because the fuel is injected above and typically aimed at the intake valve, intake valve deposits (IVD) can accumulate rapidly (Russell et al. 2013) in the absence of appropriate fuel additives. Direct injection aims the fuel directly into the combustion chamber. Because the fuel in a direct injection engine is injected directly into the combustion chamber (Figure A-2), the tip of the injector is exposed to much higher heat and pressure than in other injector configurations. Injectors accumulate deposits both on the inside and outside of the injector (Russell et al. 2013).

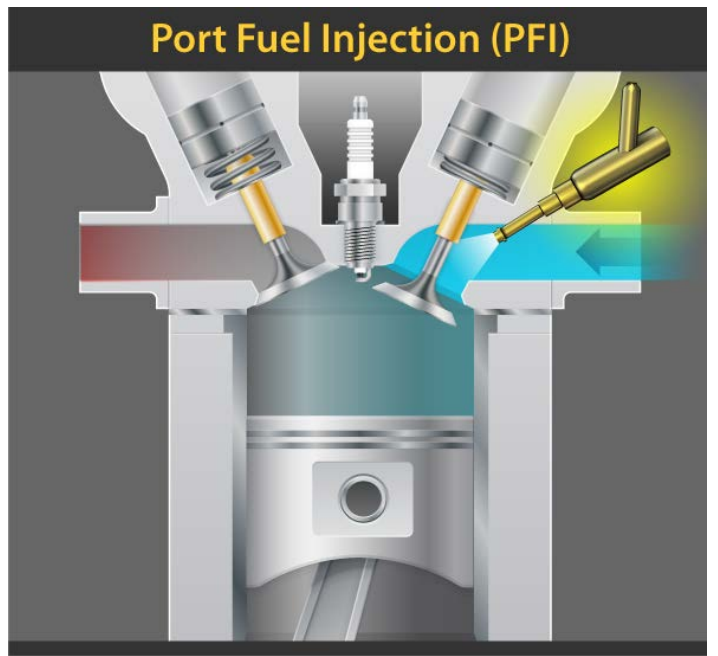

Figure A-1. Schematic of port fuel injector Image by Al Hicks, NREL

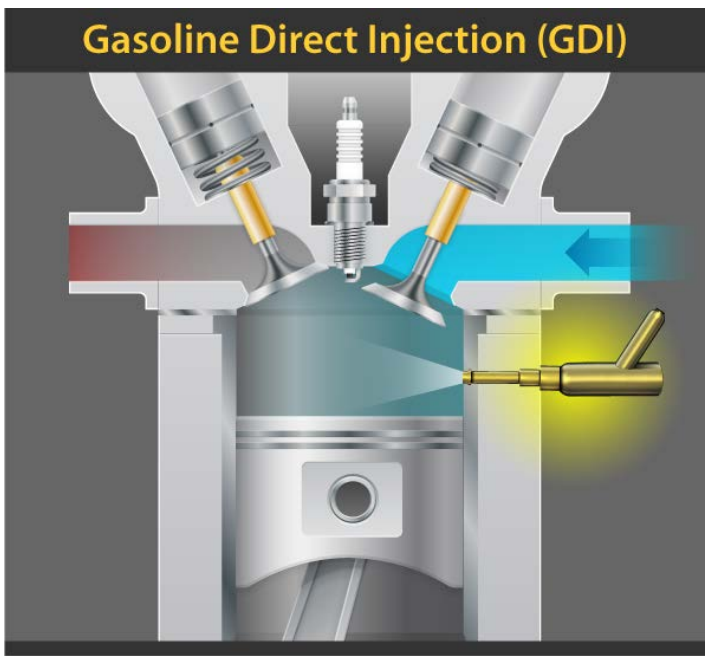

Figure A-2. Schematic of direct injection Image by Al Hicks, NREL 
In the mid-2000s, most cars had port fuel injection. Thus, the anecdotal evidence of injector sticking and contamination from that time period as discussed above was presumably primarily associated with port fuel injectors. However, research in the scientific literature on fuel system deposits in port fuel injectors focuses primarily on deposits that occur on the intake valves, immediately downstream of the port fuel injector. IVD has been studied for decades (Bitting et al. 1987, Gething 1987). Only more recently has research on direct injectors focused on deposits on and inside the injector.

Injector deposits can reduce injector fuel flow rates and lead to changes in spray characteristics. Because the spray rate, direction, and pattern have been finely optimized, changes can lead to higher emissions and less efficient combustion. Similar claims have been made for deposits on the intake valves (Chapman et al. 2013), although the impact is not as clearly measurable. Older (pre-1990) studies have also linked IVD to impacts on vehicle driveability (Bitting et al. 1987), fuel economy and engine power (Gething 1987).

Composition of the deposits has been determined using energy dispersive spectroscopy (Fernandes et al. 2012). Methodologies for quantifying and comparing injector and intake valve deposits have included weighing the equipment before and after use (Chapman et al. 2013) and visual studies using scanning electron microscopes (Fernandes et al. 2012). More extensive analyses of the composition and topography of deposits have been made using Fourier transform infrared spectroscopy microscopy, thermal desorption-gas chromatography-mass spectrometry, and a proprietary Alicona Infinite Focus3D Microcoordinate system (Dearn et al. 2014).

Deposits that impact injector flow rates can also be quantified by weighing the injector (DuMont et al. 2007) before and after a set operation cycle, measuring changes in injection time or measuring differences in flow rates (Fernandes et al. 2012). Electronic controls ensure that appropriate levels of fuel enter the engine regardless of injector fouling. Injectors that are open increasingly longer over the course of a test suggest that the flow rate has been compromised by deposits. Long-term fuel trim, as assessed using the on-board diagnostic system, provides similar information (Russell et al. 2013, Smith and Imoehl 2013).

\section{A.1 Deposit Test Methods}

ASTM has standardized several test procedures that can be used to build deposits on fuel injectors and intake valves so that fuels and deposit control additives (DCAs) can be compared. Those standards are listed in Table A-1.

Table A-1. ASTM Standards for Test Cycles for Comparing Effect of Fuels and Deposit Control Additives

\begin{tabular}{lll}
\hline $\begin{array}{l}\text { Test } \\
\text { Method }\end{array}$ & Title & Scope \\
\hline $\begin{array}{l}\text { D5598-01 } \\
(2012)\end{array}$ & $\begin{array}{l}\text { Standard Test Method for Evaluating Unleaded } \\
\text { Automotive Spark-Ignition Fuel for Electronic } \\
\text { Port Fuel Injector Fouling }\end{array}$ & $\begin{array}{l}\text { Builds deposits on port fuel injectors in a } \\
\text { consistent manner - vehicle test } \\
\text { procedure }\end{array}$ \\
D6421- & $\begin{array}{l}\text { Standard Test Method for Evaluating } \\
\text { A9a }\end{array}$ & $\begin{array}{l}\text { Builds deposits on port fuel injectors in a } \\
\text { consistent manner - bench test } \\
\text { procedure }\end{array}$ \\
\hline
\end{tabular}




\begin{tabular}{|c|c|c|}
\hline $\begin{array}{l}\text { Test } \\
\text { Method }\end{array}$ & Title & Scope \\
\hline $\begin{array}{l}\text { D5500-16 } \\
(2016)\end{array}$ & $\begin{array}{l}\text { Standard Test Method for Vehicle Evaluation of } \\
\text { Unleaded Automotive Spark-Ignition Engine } \\
\text { Fuel for Intake Valve Deposit Formation }\end{array}$ & $\begin{array}{l}\text { Builds deposits on intake valves in a } \\
\text { consistent manner - vehicle test } \\
\text { procedure }\end{array}$ \\
\hline $\begin{array}{l}\text { D6201-04 } \\
(2014)\end{array}$ & $\begin{array}{l}\text { Standard Test Method for Dynamometer } \\
\text { Evaluation of Unleaded Spark-Ignition Engine } \\
\text { Fuel for Intake Valve Deposit Formation }\end{array}$ & $\begin{array}{l}\text { Builds deposits on intake valves in a } \\
\text { consistent manner - dynamometer }\end{array}$ \\
\hline
\end{tabular}

A minimum concentration of DCAs is required by the EPA in all reformulated and conventional gasolines and the gasoline component of flex fuel (Dumont et al. 2007) because it is well known that IVD impacts tailpipe emissions (Houser and Crosby 1992).

Although the EPA sets minimum DCA levels, eight automakers have determined that increased levels of DCAs in gasoline will enhance engine cleanliness. In conjunction with gasoline retailers, the Top Tier ${ }^{\mathrm{TM}}$ program was developed to provide gasoline with increased performance, validated through quantifiable performance on a series of engine deposit and injector performance tests (Top Tier 2016).

Corrosion inhibitors are added to both gasoline and ethanol to minimize internal corrosion of the fuel distribution system. They operate by passivating the metal surfaces. However, corrosion inhibitors have been found in some cases to increase injector and intake valve deposits.

\section{A.2 Testing Results}

In a comprehensive review, $\mathrm{Xu}$ and coworkers (2015) found that literature sources primarily associate injector deposit formation with the oxidation, condensation, and precipitation of hydrocarbons from gasoline. The composition of the fuel affects the amount of deposits. Higher olefin and aromatic content increase the quantity of deposits, and a higher T90 has a similar but smaller effect (Carlisle et al. 2001). The temperature of the injector tip is also believed to affect the amount of deposits, with cooler temperatures leading to fewer deposits (Xu et al. 2015).

When DCAs are not included, ethanol has been found to reduce injector deposits in comparison to gasoline (Ashida et al. 2001). Whether this is because ethanol leads to lower injector nozzle temperatures compared to gasoline, ${ }^{4}$ because it has a detergent effect, or because it is a source of fewer deposit-forming precursors is not clear.

Fernandes and coworkers (2012), using Brazilian E25 fuels, found that the predominant deposits formed in gasoline direct injection engines were inorganic compounds, including sodium sulfate and potassium sulfate, although significant deposits of carbon were also found. The proportion of or how large these deposits were was not specified. Using two fuels with sulfate contents differing only between $0.79 \mathrm{mg} / \mathrm{kg}$ and $0.91 \mathrm{mg} / \mathrm{kg}$, they found that the correction factor from the injection time (which they term "FRA" and is comparable to long-term fuel trim) rose far faster for the higher-sulfate fuel. However, because they used only two fuels that differed in numerous ways and had fairly similar sulfate levels, attributing this variation only to the sulfate concentration seems unwarranted. They also tested six different unnamed market fuel additives

\footnotetext{
${ }^{4}$ Tanighui cited in $\mathrm{Xu}, 2015$.
} 
intended to treat carbonization deposits and found that none of the additives was effective at reducing injector deposits for the E25 fuels they tested.

Russell and coworkers (2013) conducted engine tests on several cellulosic ethanols in E15 and E70 blends. One of the tested cellulosic ethanols had higher levels of deposits than the others, but all the tested ethanols had very low levels of sulfate $(<1 \mathrm{mg} / \mathrm{kg})$. There was no evidence that this level of sulfate had any adverse impact on the amount of deposits as the E0 baseline fuel resulted in more IVD (in port fuel injector engines) and bigger changes in long-term fuel trim (in direct injection engines) than the higher concentration fuels.

Vilardo and coworkers (2007) conducted 81 paired tests of fuels on ASTM D5500 and compared IVD. The paired test matrix held the base fuel and additive treat rate the same, varying only ethanol content between E0 and E10. Several base fuels, additives, and treat rates were compared in the protocol. They found that, on average, the E10 tests produced greater IVD; however, they did not break out their results by additive dose, so it is not clear whether dilution of the DCA dose with ethanol was the cause of this disparity. Nor did they provide sulfate levels in the ethanol. The effect of E10 on IVD appears to increase with increasing valve temperature. Higher levels of ethanol (E85) were found to reduce IVD below the levels of straight gasoline and a Top Tier dose of DCA throughout the blend (not just the gasoline portion) reduces deposit levels by an order of magnitude.

Chapman and coworkers (2013) studied the impact of corrosion inhibitors on the IVD in port fuel injector engines. They showed that corrosion inhibitors increase the amount of IVD in the engine regardless of the ethanol concentration. The impact varies depending on the type of corrosion inhibitor.

DuMont and coworkers (2007) measured IVD in a 2006 GM Chevrolet flex-fuel vehicle (FFV) Impala run over a representative chassis dynamometer test cycle, using conventional gasoline and E85 with and without additives. The goal of the program was to compare different sources of ethanol, including sulfate content and different corrosion inhibitors, on deposit formation in an FFV. An FFV was chosen for testing in response to the Milwaukee station filter plugging and vehicle issues reported in 2004 and discussed previously. The hypothesis was that vehicle problems may be exacerbated in an FFV running E85 due to the significantly lower portion of gasoline, and hence additives, in the fuel.

Initial testing on the FFV showed deposits forming in unadditized gasoline and a notable reduction when the gasoline was additized to Top Tier levels with a polyisobutylene amine (PIBA) additive. The Top Tier additization levels are typically 2 to 3 times the EPA-mandated levels in conventional gasoline. The impact of deposits in the FFV was confirmed using the D6201 test, using a Ford 2.3L engine, and the FFV was used throughout the test protocol.

Because one of the goals in the test program was to vary ethanol supply, a baseline test was conducted using E85 with no additive in the gasoline portion of the blend produced from ethanol "A" and ethanol "B." Ethanol "A" contained 3.8 ppm sulfate and a corrosion inhibitor (sodium was measured at $3 \mathrm{ppm}$ in the ethanol), and ethanol "B" contained $<1 \mathrm{ppm}$ sulfate and no corrosion inhibitor. The results from the tests showed much higher deposits on ethanol " $\mathrm{A}$ " than 
ethanol "B," beyond what can be explained from the contribution of engine oils on IVD. All subsequent tests were conducted on ethanol "A."

The PIBA additive concentration in the E85 using ethanol " $\mathrm{A}$ " were varied by dosing the gasoline at various levels and calculating the finished treat rate in the blend. The data are summarized in Table A-2. The measured IVD decreased with increasing treat rate in the gasoline portion of the E85. Additional testing using a polyether amine additive confirmed the reduction in IVD with increasing additive concentration in the gasoline portion of the E85.

At the end of the test protocol, an in-depth test of deposits in the intake valves was conducted. This analysis found that sodium and sulfate concentrations in the deposits were well correlated, indicating the presence of sodium sulfate salt in the deposit. A mass balance found that sodium and sulfate were not balanced from ethanol "A," but were from ethanol "B." The authors conclude that some of the sulfate was bound in organic matrices.

Beyond the sulfate concentration in the ethanol, another major difference was the presence of corrosion inhibitor in the ethanol. Since ethanol "B" contained minimal levels of an inhibitor, the ethanol was treated to the same dosage with inhibitor in ethanol " $A$ " and with an inhibitor without buffering. These tests revealed that addition of a buffered inhibitor to E85 resulted in IVD, while the impact of an unbuffered inhibitor did not.

Injector tip analysis also found sodium sulfate salts present. Due to the relatively short duration of the test, the deposits were not significant enough to impact injector performance, their presence was significant.

Table A-2. Summary of IVD Deposit Testing on a Chevrolet FFV using E85 and Conventional Gasoline with various Additive Chemistries and Treat Rates

\begin{tabular}{|c|c|c|c|c|c|c|}
\hline Test Fuel & $\begin{array}{l}\text { Ethanol } \\
\text { Content }\end{array}$ & $\begin{array}{l}\text { Fuel } \\
\text { treated }\end{array}$ & $\begin{array}{l}\text { Additive } \\
\text { Type }\end{array}$ & $\begin{array}{l}\text { Additive } \\
\text { Treat Rate }\end{array}$ & IVD & Notes \\
\hline $\begin{array}{l}\text { Conventional } \\
\text { gasoline }\end{array}$ & 0 & None & None & NA & $429 \mathrm{mg}$ & \\
\hline $\begin{array}{l}\text { Conventional } \\
\text { gasoline }\end{array}$ & 0 & Gasoline & PIBA & 324 ppm & $5 \mathrm{mg}$ & $\begin{array}{l}\text { Top Tier gasoline treat } \\
\text { rate }\end{array}$ \\
\hline $\begin{array}{l}\text { E85 with } \\
\text { ethanol "A" }\end{array}$ & 84 vol\% & Ethanol & $\begin{array}{l}\text { Corrosion } \\
\text { inhibitor } X\end{array}$ & 116 ppm & & \\
\hline $\begin{array}{l}\text { E85 with } \\
\text { ethanol "B" }\end{array}$ & 84 vol\% & Ethanol & $\begin{array}{l}\text { Corrosion } \\
\text { inhibitor } X\end{array}$ & 3 ppm & $99 \mathrm{mg}$ & \\
\hline $\begin{array}{l}\text { E85 with } \\
\text { ethanol "A" }\end{array}$ & 84 vol\% & Gasoline & PIBA & $\begin{array}{l}114 \text { ppm in } \\
\text { gasoline }\end{array}$ & $191 \mathrm{mg}$ & $\begin{array}{l}\text { Gasoline was treated } \\
\text { to EPA minimum levels } \\
\text { for 18-ppm PIBA in } \\
\text { finished fuel }\end{array}$ \\
\hline $\begin{array}{l}\text { E85 with } \\
\text { ethanol "A" }\end{array}$ & 84 vol\% & Gasoline & PIBA & $\begin{array}{l}324 \text { ppm in } \\
\text { gasoline }\end{array}$ & $134 \mathrm{mg}$ & $\begin{array}{l}\text { Gasoline was treated } \\
\text { at Top Tier additive } \\
\text { levels for PIBA of } 84 \\
\text { ppm in finished fuel }\end{array}$ \\
\hline
\end{tabular}




\begin{tabular}{|c|c|c|c|c|c|c|}
\hline Test Fuel & $\begin{array}{l}\text { Ethanol } \\
\text { Content }\end{array}$ & $\begin{array}{l}\text { Fuel } \\
\text { treated }\end{array}$ & $\begin{array}{l}\text { Additive } \\
\text { Type }\end{array}$ & $\begin{array}{l}\text { Additive } \\
\text { Treat Rate }\end{array}$ & IVD & Notes \\
\hline $\begin{array}{l}\text { E85 with } \\
\text { ethanol "A" }\end{array}$ & 84 vol\% & Gasoline & PIBA & $\begin{array}{l}2,024 \mathrm{ppm} \text { in } \\
\text { gasoline }\end{array}$ & $14 \mathrm{mg}$ & $\begin{array}{l}\text { Gasoline was treated } \\
\text { to Top Tier levels in } \\
\text { finished fuel, PIBA } \\
\text { level of } 324 \text { ppm in } \\
\text { E85 }\end{array}$ \\
\hline $\begin{array}{l}\text { E85 with } \\
\text { ethanol "A" }\end{array}$ & 84 vol\% & Gasoline & PEA & $\begin{array}{l}953 \mathrm{ppm} \text { in } \\
\text { gasoline }\end{array}$ & $92 \mathrm{mg}$ & $\begin{array}{l}\text { Finished fuel treat rate } \\
\text { was } 152 \mathrm{ppm}\end{array}$ \\
\hline $\begin{array}{l}\text { E85 with } \\
\text { ethanol "B" }\end{array}$ & 84 vol\% & Gasoline & PEA & $\begin{array}{l}11,912 \mathrm{ppm} \\
\text { in gasoline }\end{array}$ & $4 \mathrm{mg}$ & $\begin{array}{l}\text { Finished fuel treat rate } \\
\text { was } 1,906 \mathrm{ppm}\end{array}$ \\
\hline $\begin{array}{l}\text { E85 with } \\
\text { ethanol "B" }\end{array}$ & 84 vol\% & Ethanol & $\begin{array}{l}\text { Corrosion } \\
\text { inhibitor X }\end{array}$ & 116 ppm & $230 \mathrm{mg}$ & $\begin{array}{l}\text { Buffered corrosion } \\
\text { inhibitor }\end{array}$ \\
\hline $\begin{array}{l}\text { E85 with } \\
\text { ethanol "B" }\end{array}$ & 84 vol\% & Ethanol & $\begin{array}{l}\text { Corrosion } \\
\text { inhibitor } Y\end{array}$ & 116 ppm & $81 \mathrm{mg}$ & $\begin{array}{l}\text { Unbuffered corrosion } \\
\text { inhibitor }\end{array}$ \\
\hline
\end{tabular}

PEA: polyether amine

PIBA: polyisobutylene amine 


\section{Appendix B: Control of Sulfate Salts in Blendstocks}

\section{B.1 Denatured Fuel Ethanol}

In speaking with various ethanol producers, we learned that internal sulfate controls are in place to limit sulfate concentration in ethanol. As shown in Figure 5, these controls do a very good job of limiting sulfate at the production facility. Though specific details of sulfate monitoring and control were not discussed, two processes to remove sulfate from ethanol are discussed here.

One solution is a unit sold by U.S. Waters that is integrated into the ethanol production facility. The unit, called the "Ethanol Final Filter," can be added to an ethanol production plant to remove sulfate from fuel ethanol and has the advantage of removing other impurities. ${ }^{5}$ The second solution is a clay removal method to reduce sulfates (and chloride) in ethanol, which was patented by ConocoPhillips in $2007 .{ }^{6}$ The process is applicable not only to fuel ethanol, but also to gasoline-ethanol blends.

The likely cation for sulfate salts in ethanol is hydrogen. Other cations are at very low levels and normally insufficient to balance the anions.

\section{B.2 Hydrocarbon Blendstocks}

Further information needs to be collected on the controls petroleum refineries use for limiting the cations and anions in the hydrocarbon blendstocks and water that may move downstream with the blendstocks.

\footnotetext{
${ }^{5} \mathrm{http}: / /$ www.ethanolfinalfilter.com/

${ }^{6}$ https://www.google.com/patents/US20070249487
} 